\title{
La cuestión nacional judía en el socialismo de Europa del Este: disputas partidarias e internacionales (1892-1914)
}

\section{The Jewish National Question in Eastern European socialism: party and international disputes (1892-1914)}

\author{
Manuel Quiroga* - Mariana Massó**
}

\begin{abstract}
Resumen: En este artículo analizamos los debates y disputas políticas en la Social Democracia sobre la cuestión nacional judía. Nos enfocamos en distintas organizaciones políticas de varias zonas de Europa oriental: El Imperio Ruso, donde abordamos las relaciones entre el Bund y el resto de la Social Democracia Rusa; la zona polaca del Imperio (la Polonia del Congreso), donde analizamos las relaciones entre el Bund, la Social Democracia Polaca y el Partido Socialista Polaco (PPS); finalmente nos enfocamos en la provincia de Galitzia, en ese momento parte de Austria, para evaluar la disputa entre el Partido Social Demócrata Polaco de Austria (parte del partido Pan-Austríaco) y los activistas judíos que, viniendo de este partido, rompieron con el mismo para crear un partido judío de orientación bundista. En todos los casos examinados combinamos un análisis de las posiciones que estas distintas organizaciones desarrollaron sobre la cuestión nacional judía, enmarcadas en sus disputas y debates generales. Nos centramos en sus posiciones sobre la existencia de la nacionalidad judía, su posición sobre el futuro de la población judía (asimilacionista, neutralista, nacionalista, etc.) y la relación de estas cuestiones con una posición general sobre el problema nacional. Este trabajo se centra en analizar las regiones donde surgieron distintas posturas sobre la conveniencia de una organización socialista judía, factor que estimuló el conjunto del debate sobre la cuestión nacional judía. Finalizamos analizamos la lucha que algunas organizaciones socialistas judías libraron por ser reconocidas por la Segunda Internacional y los cruces internacionales entre las distintas posturas.
\end{abstract}

Palabras clave: Bund, Social Democracia Rusa, Cuestión Judía, Socialismo Polaco, Socialismo en Galitzia, Antisionismo judío

\footnotetext{
* Manuel Quiroga: Argentino, Licenciado en Historia, Becario Doctoral del CIECS-CONICET en Córdoba, Programa de Historia Contemporánea

*** Mariana Massó: Argentina, Profesora en Historia, Universidad Nacional de Córdoba.
} 


\begin{abstract}
In this article we analyze the debates and political disputes in the Second International about the Jewish Question as a national question. We focus on different political organizations of various zones of Eastern Europe: The Russian Empire, where we address the relations between the Bund and the rest of Russian Social Democracy; the polish zone of the Empire (Congress Poland), where we analyze the relations between the Bund, Polish Social Democracy and the Polish Socialist Party (PPS); finally, we focus on the Province of Galitzia, in that moment a part of Austria, to assess the struggle between the Polish Social Democratic Party of Austria (part of the All-Austrian party) and the Jewish activists that, coming from this party, broke with it to create a Jewish party of bundist orientation. In all the examined cases we combine an analysis of the positions that these different organizations developed over time about the Jewish national question, framed in their general disputes and debates. We focus in their positions about the existence of a Jewish nationality, their position on the future of Jewish population (assimilationist, neutralist, nationalist, etc.) and the relationship of these questions with a general position on the national question. This work focuses in analyzing the regions where different positions on the convenience of a separate Jewish socialist organization emerged, a factor that stimulated the whole debate on the Jewish National Question. We finish by analyzing the struggle that some socialist Jewish organizations fought to be recognized by the Second International and the international connections between the different postures.
\end{abstract}

Keywords: Bund, Russian Social Democracy, Jewish Question, Polish Socialism, Socialism in Galitzia, Jewish Anti-Zionism

Recibido:

Aceptado:

\title{
Introducción
}

El presente trabajo lidia con los debates y disputas políticas en la Segunda Internacional en torno a la consideración de la cuestión judía como cuestión nacional. Estos debates tenían una doble articulación: por un lado, se vinculaban con debates generales sobre la cuestión nacional, donde distintos teóricos de la Social Democracia de la época, a través de sus escritos, brindaron opiniones generales sobre la cuestión nacional, y sobre el lugar de los judíos en este marco. Por otro lado, este debate tuvo un aspecto más práctico-político a partir del surgimiento de diversas organizaciones en Europa del Este que tuvieron distintas posiciones sobre el estatus de los judíos expresadas en propuestas organizativas y líneas políticas concretas. Este trabajo aborda e interrelaciona ambos aspectos: los escritos

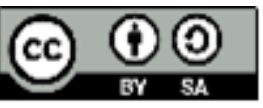


teóricos de referentes del socialismo internacional de la época (en particular de Lenin, Rosa Luxemburg, Otto Bauer ${ }^{1}$ y Kautsky ${ }^{2}$ ) y las posiciones de distintas organizaciones ${ }^{3}$.

Para ambos ejes hemos acudido a numerosas fuentes primarias, tanto escritos de los teóricos como distintos documentos partidarios que han sido traducidos y editados en castellano y en inglés. Para fuentes donde no tenemos el necesario conocimiento de idiomas (yiddish, ruso, polaco, etc.) y donde no hay versiones traducidas, nos hemos basado en reconstrucciones de la amplia bibliografía secundaria ${ }^{4}$. Los dos ejes que atraviesan el trabajo son las opiniones y debates sobre la nacionalidad judía en sí (su existencia, propensión o no a la asimilación, necesidad o no de un trabajo político específicamente nacional, etc.) y, por otro lado, la cuestión partidaria y organizativa asociada a esto (la conveniencia de organizaciones separadas por nacionalidad, su aplicación o no a la población judía, etc.). Estos ejes serán abordados en primer lugar por zona (Rusia, Polonia y Galitzia, provincia oriental del Imperio Austro-Húngaro), con un cuarto apartado que aborda algunos cruces de estos dos ejes a nivel internacional, agregándole el tema de la lucha entre las organizaciones socialistas y social-sionistas por el reconocimiento de la

${ }^{1}$ Otto Bauer(1881- 1938): Fue uno de los principales teóricos de la Social Democracia Austríaca. Miembro de la escuela Austro-marxista.

${ }^{2}$ Karl Kautsky(1854 - 1938): Principal teórico de la Social Democracia alemana.

${ }^{3}$ Nuestro trabajo se centra en las organizaciones Social-Demócratas (que en el lenguaje de la época denominaba a partidos marxistas, generalmente con distintas tendencias internas). También abordamos al PPS, partido polaco que se denominaba socialista y no Social Demócrata. No obstante, la orientación general de su programa era marxista, con una particular interpretación de la cuestión nacional. Excluimos a las importantes organizaciones del socialismo populista ruso, por razones de unidad temática y espacio, así como de insuficiente bibliografía y fuentes como para presentar un análisis comprehensivo. Sólo hacemos una referencia breve en el análisis del apartado 4, relevante para analizar la lucha de las organizaciones socialistasionistas por ser reconocidas por la Segunda Internacional.

${ }^{4}$ Con respecto a la bibliografía disponible, cabe destacar que el presente trabajo, constituye el primer esfuerzo en lengua castellana por abordar de manera internacional la problemática de la cuestión nacional judía en la Segunda Internacional. Recupera así diversos trabajos recientes en inglés que han abordado el tema. Discute con las interpretaciones de los autores que analizan el conflicto entre el Bund y el Partido Obrero Social Demócrata Ruso (RSDRP) como la demostración de una serie de volteretas oportunistas de Lenin para dominar a los Social Demócratas judíos (Gechtman 2008) y con la idea de que su posición frente a la nacionalidad judía era parte simplemente de una posición general sobre la cuestión nacional y la tendencia a la homogeneización nacional (Peled 1987). Para esto reconstruimos en detalle el complejo escenario de luchas internas partidarias que fueron definiendo las posiciones de Lenin y la fracción bolchevique sobre la cuestión nacional judía, y que muestran un panorama más complejo. A su vez, recuperamos el trabajo de Zimmerman (2004) que muestra lo importante que fue para las definiciones del Bund la influencia del socialismo independentista polaco, y viceversa; no obstante, tratamos de corregir cierto reduccionismo del autor, que tiende a atribuirle cada giro dado por estas organizaciones a su relación entre sí. Creemos que la mirada internacional corrige este sesgo. A su vez, recuperamos una comparación valiosa con el socialismo judío de Galitzia, compartiendo la interpretación de los trabajos de Kuhn (2007 y 2011). Aprovechamos las fuentes primarias editadas en inglés en trabajos como el de Pearce (1978), Harding y Taylor (1983), y Mullin (2015).

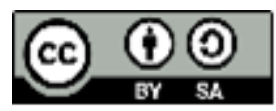


Segunda Internacional.

En el caso de la división de zonas entre Rusia y Polonia, es necesario tener en cuenta que ambas formaban parte de la misma unidad política en ese momento (el Imperio Ruso), y que legalmente los judíos del Imperio Ruso sólo podían vivir normalmente en la parte del Imperio conocido como Zona de Asentamiento (Pale of Settlement en inglés), que incluía una pequeña parte occidental de lo que hoy es Rusia y el territorio actual de lo que hoy es Ucrania, Moldavia, Lituania, Letonia, Bielorrusia, y parte de la actual Polonia. Sólo en algunos casos excepcionales podían residir en otras zonas. En dicho momento histórico, el territorio de una unidad política anterior, la Mancomunidad de Polonia y Lituania, había sido desmembrada entre tres potencias: Prusia, Austria y Rusia, con la población polaca y judía dividida entre estas tres zonas. Así, las organizaciones socialistas en Polonia tendían a organizarse separadamente, y el problema nacional polaco se entremezclaba con la cuestión judía en formas variables en esta zona. Así, más que a una división geográfica estricta, esta división corresponde a campos de debate entre organizaciones políticas determinadas. Así, el recorte geográfico se centra en la zona de cultura polaca, dividida entre varios Estados, y otras regiones de la Zona de Asentamiento del Imperio ruso. Esto obedece a que fue en estas zonas donde surgieron debates sobre la organización separada de los judíos en organizaciones socialistas propias; intentaremos demostrar que el hecho de que se planteara la escisión organizativa fue un factor político fundamental para que se estimulara el conjunto del debate sobre la cuestión nacional judía.

En el marco de la Segunda Internacional, este debate tendió a concentrarse en Europa del Este. La población judía de la zona tenía características particulares: era una población que compartía un idioma común (el Yiddish), tendía a agruparse espacial y socialmente en forma más segregada, y sufría una situación de opresión mucho más aguda, en particular en los territorios del Imperio Ruso, que la distinguían de la población judía de los países de Europa Occidental (la cual, normalmente, estaba asimilada lingüísticamente a las naciones de los lugares donde habitaba). No abordaremos discusiones sobre el problema en Europa Occidental.

Como ya hemos dicho, el presente trabajo está dividido en el abordaje de tres zonas relevantes para el estudio de este debate. En primer lugar, se abordan los debates de las organizaciones socialistas que pretendían organizarse a escala del Imperio Ruso, en particular la organización judía del Bund y el Partido Obrero Social Demócrata de Rusia $\left(\right.$ RSDRP $\left.^{5}\right)$ a quienes se sumaron posteriormente organizaciones que expresaban distintos matices del autodefinido "Sionismo Socialista". En segundo lugar, abordamos los debates sobre la cuestión nacional entre las distintas organizaciones que operaban en la zona polaca y lituana del Imperio Ruso, en particular el PPS (por su sigla en polaco; Partido Socialista

\footnotetext{
${ }^{5}$ Todas las siglas de organizaciones políticas están citadas en su idioma original.
} 
Polaco) y sus distintas fracciones, la SDKP (Social Democracia del Reino de Polonia) y el Bund. En tercer lugar, abordaremos un caso poco conocido: la organización de un partido Social Demócrata Judío en Galitzia, una parte de Austria donde dominaba la etnia polaca, y su intento de conseguir el reconocimiento por parte del Partido Pan-Austríaco (dividido en secciones nacionales). En cuarto lugar, analizaremos los cruces internacionales en las posturas sobre la nacionalidad judía y la forma de organización, así como la lucha de las distintas organizaciones socialistas judías por conseguir reconocimiento de la Segunda Internacional.

Así, este trabajo se coloca en el cruce de tres grandes cuestiones, comunes a los distintos casos analizados: la cuestión judía, la cuestión nacional en general, y los distintos formatos organizativos de los partidos socialistas de la época. Ahora bien, antes de introducirnos en los casos particulares, introducimos el aspecto internacional de estos debates. En torno a la cuestión judía, la Segunda Internacional periódicamente sacaba declaraciones condenando al antisemitismo, sobre todo ante hechos relacionados con Rusia: por ejemplo, ante la reducción del número de estudiantes rusos admitidos en las Universidades en 1901, y ante un gran pogrom en 1903. En 1904 la Internacional sacó una larga declaración condenando el antisemitismo ruso en general (Mendelsohn 1964: 132). Sin embargo, este planteo de simpatía con la causa de los judíos oprimidos no implicaba el reconocimiento de un estatus nacional, como veremos en los casos analizados. En relación a la cuestión nacional, la Segunda Internacional, si bien promovía el internacionalismo, también admitía la lucha contra la opresión nacional y se declaraba por la autonomía nacional plena. A su vez, también aceptaba la representación de organizaciones socialistas de nacionalidades sin Estado, como por ejemplo a las polacas (Mendelsohn 1964: 131-132). Los años siguientes se darían importantes polémicas en torno a la interpretación de la cuestión nacional, que veremos reflejadas en la cuestión nacional judía. Pero donde realmente la cuestión se volvió un problema político fundamental, fue cuando se entremezcló con el problema organizativo de los partidos socialistas. En general predominaban en la Segunda Internacional modelos centralizados de partidos socialistas que no distinguían a sus miembros por nacionalidad. No obstante, existió un precedente fundamental para el planteo de organizaciones separadas por nacionalidad: el ejemplo austríaco, que en 1897 fue reorganizado como un partido federal, dando autonomía a los partidos de las distintas nacionalidades (Austro-Alemán, Checo, Austro-Polaco, etc.), unidos por un liderazgo y un Congreso Pan-Austríaco que, se suponía, debía reunirse cada dos años, a la vez que cada partido mantenía sus propios líderes y congresos Al mismo tiempo, este partido emitió, en el Congreso en Brno de 1899, una resolución que planteaba una solución federal para el problema nacional, dividiendo Austria en zonas nacionales separadas (Kogan 1949: 206-208). En años posteriores, el partido debatiría intensamente la cuestión nacional, e iría ganando terreno una posición favorable a la autonomía nacional extra territorial (aunque sin reemplazar oficialmente a la resolución de Brno), es decir, el reconocimiento de derechos nacionales a través de

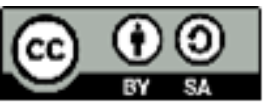


organismos públicos de cada nacionalidad sin importar la zona donde habitaran. Esta posición, asociada sobre todo con Bauer (1907) tendría una importante influencia en los casos que analizaremos.

\section{Primera Parte: Rusia}

\section{Los judíos en el Imperio ruso y Polonia}

El surgimiento de las organizaciones socialistas que pretendían representar a la población judía del Imperio ruso y Polonia, se dio sobre la base de una gran transformación de la población. Siguen algunos datos que permiten situar el lugar de los judíos en este marco: 5.19 millones de judíos habitaban el Imperio ruso, 4,13\% de la población total. El $93.9 \%$ de estos vivía dentro de la así llamada Zona de Asentamiento. El 96.9\% de los judíos del Imperio tenía al Yiddish como primer idioma. En Polonia había un porcentaje de aculturación levemente mayor que en otras zonas: 3.5\% de los judíos hablaba polaco como primer idioma. En Polonia, los judíos correspondían al $14.1 \%$ de la población, pero conformaban el $44 \%$ de la población urbana, teniendo así una incidencia considerablemente mayor a su porcentaje total en las ciudades, donde concentraba su actividad el movimiento socialista de la época. De los trabajadores asalariados judíos en toda la Zona de Asentamiento, la inmensa mayoría (85\%) estaba concentrada en pequeños talleres de trabajo artesanal de oficio (tales como carpintería y sastrería). El 15\% restante trabajaba en la industria. Uno de las trabas importantes para el acceso de los judíos a los trabajos industriales era el problema del descanso en el Shabbat (Zimmerman 2004: 13-17).

\section{El surgimiento del Bund y la disputa por su posición en la Social Democracia Rusa (1897 - 1903)}

Los orígenes del Bund se remontan al surgimiento del llamado Grupo de Vilna, agrupación de judíos Social Demócratas que luego se expandió desde esa ciudad a otras ciudades de la Zona de Asentamiento, incluyendo Varsovia. En un primer momento, los objetivos del Grupo de Vilna implicaban agitar entre los trabajadores judíos y formar parte del movimiento Social Demócrata Ruso. En su plataforma programática, no se encuentran demandas relacionadas con la población judía, sino que se centraron en demandas fundamentalmente económicas. Sin embargo, a partir de 1893 se dio un cambio en la política del Grupo de Vilna. A partir del panfleto de Kremer" y Martov", "Sobre la

\footnotetext{
${ }^{6}$ Arkadi Kremer (1865-1935): Ingresó al Grupo de Vilna en 1891, donde rápidamente se posicionó como líder de la organización que le daría origen al Bund, reemplazando a Kopelzon (fundador del Grupo de Vilna junto con Lev Jogiches). Posteriormente llegó a ser conocido como "el padre del Bund".
} 
agitación", se puso en discusión un cambio en la táctica del movimiento Social Demócrata con el objetivo de masificar las luchas y la organización. Se apeló a una política de agitación y propaganda de demandas políticas y económicas, en el idioma de los trabajadores judíos, el Yiddish (Kremer y Martov 1896).

En octubre de 1987 se llevó a cabo el primer congreso de socialistas judíos, que dio lugar a la fundación del "Bund General de Trabajadores Judíos de Rusia y Polonia". Dentro de las resoluciones del congreso, se declaró al Bund como defensor de los derechos civiles de los judíos y se planteó la voluntad de unificarse con el movimiento Social Demócrata de Rusia (Zimmerman 2004: 124). También, se destacó como una tarea importante continuar con la distribución de la literatura socialista en Yiddish, y se oficializó al Di arbeytershtimme como prensa del Bund, que sería controlada por Kossovsky, Mutnik ${ }^{8}$ y Kremer, quienes también formarían parte del comité central. Además, se eligió a Minsk como el nuevo centro político en donde, al año siguiente (en marzo de 1898), tuvo lugar el Congreso de fundación del partido del Partido Obrero Social Demócrata Ruso (RSDRP). Tal como querían los bundistas, el congreso resolvió que el Bund forme parte del RSDRP manteniendo cierta autonomía. Sobre ese punto, la resolución del Congreso estableció lo siguiente: "El Bund General de Trabajadores Judíos de Rusia y Polonia entra al Partido como una organización autónoma, independiente únicamente en las cuestiones que afecten específicamente al proletariado judío" (RSDRP 1898: 225). La interpretación de este párrafo sería motivo de grandes disputas en los años posteriores.

Al poco tiempo de la fundación del partido, el Bund sufrió un ataque represivo que implicó la confiscación de gran parte de sus materiales editados y el arresto de muchos de sus militantes, entre ellos los participantes del Comité central (Zimmerman 2004: 92).

Ante esta situación, en diciembre de ese año, algunos miembros del partidose exiliaron y formaron un Comité Central del Bund en el extranjero, particularmente en Ginebra. Allí establecieron al Der yidisherarbeyter como órgano oficial de la organización, a través del cual se empezarían a difundir algunos debates sobre la cuestión nacional y judía, promovidos por el editor del periódico, John Mill ${ }^{9}$. En el tercer congreso del Bund en

\footnotetext{
${ }^{7}$ Yuli Mártov (1873 - 1923): Militante Social Demócrata Judía, formó parte del Grupo de Vilna. Más adelante priorizó la militancia en el RSDRP, fue miembro del comité redactor de Iskra y, después de la ruptura del mismo en el Congreso del RSDRP de 1903 (analizado más abajo) fue líder de la fracción menchevique.

${ }^{8}$ Vladimir Kossovsky (1867-1941) y Avrom Mutnik (1868-1930): Ingresaron al Grupo de Vilna en 1891 y formaron parte del núcleo que fundó el Bund. Fueron, junto con Kremer, los elegidos para formar parte del Comité Central y la prensa del partido en Vilna.

${ }^{9}$ John Mill (1870-1952): Uno de los fundadores del Bund. Cumplió un rol particular en la organización ya que fue uno de los que lucharon por una plataforma nacional dentro del socialismo judío, y fue "(...) el primero -y por muchos años el único- Bundista en incorporar un "elemento polaco" en los círculos socialistas judíos en Lituania" (Zimmerman 2004: 41)
} 
Knovo en 1899 se visualizaron dos tendencias en torno a la cuestión nacional: el ala nacional, liderada por el Comité de Ginebra, que proponía algo similar a lo resuelto por el partido Social Demócrata de Austria: transformar a Rusia en una federación de nacionalidades con igualdad de derechos y donde cada una tenga autonomía cultural; la otra postura, sostenida por el Bund de Varsovia, se oponían a que el partido tome una definición en torno a la cuestión nacional. Este primer debate no tuvo consecuencias en este Congreso sobre la línea oficial del partido (Zimmerman 2004:117).

Posteriormente, una serie de hechos llevaron al fortalecimiento de la tendencia nacionalista. Por un lado, los viejos miembros del primer comité central salieron de prisión y se posicionaron a favor de la línea de Ginebra; por otro lado, el surgimiento de las organizaciones sionistas y del PPS, le impusieron al Bund la necesidad de elaborar una posición oficial sobre la cuestión nacional y judía. Esto se manifestó en el Cuarto Congreso del Bund, en Bialystok en 1901, donde resolvieron que:

El congreso sostiene que un Estado como Rusia, que contiene muchas nacionalidades, debería, en el futuro, reestructurarse como una federación de nacionalidades donde cada una tenga completa autonomía nacional, independientemente del territorio en el que se encuentra. La conferencia sostiene que el término "nación" es, también, aplicable al pueblo judío. Sin embargo, considerando prematuro por el momento levantar la demanda de autonomía nacional para los judíos, el Congreso encuentra suficiente (...) luchar por el rechazo de todas las leyes espaciales contra los judíos y protestar contra casos de opresión de la nación judía, al tiempo que evitamos inflamar el sentimiento nacional, que es capaz únicamente oscurecer la conciencia de clase del proletariado y de llevarlo al chauvinismo (Bund 1901: 309).

\section{Hacia el Segundo Congreso de la Social Democracia Rusa}

Las nuevas posiciones sobre la cuestión nacional del Bund irían decantando en una disputa teórica y organizativa con otros sectores del RSDRP. La disputa comenzaría desde antes de que celebrara el Congreso y tendrían gran influencia en el desarrollo del mismo.

Una primera polémica con Lenin surgiría a partir de la publicación de dos artículos en el órgano del comité del Bund en el extranjero, Poslednie Izvestiia. El primero criticaba al Comité de Ekaterinoslav por publicar una proclama contra el sionismo, la cual criticaba la idea de un pueblo judío unificado sin hacer ninguna referencia a la existencia del movimiento obrero judío, y en particular al Bund. De esto concluían que: "nuestros camaradas en el comité de Ekaterinoslav todavía no han digerido la idea de la necesidad de 
una organización separada para las fuerzas del proletariado judío" (Poslednie Izvestiia 1903a: 316-7). El segundo artículo criticaba que el Bund haya sido excluido de las reuniones del Comité Organizador del próximo Congreso del RSDRP, y que éste hubiese publicado una declaración sin consultarles; incluso aunque el anuncio del Comité planteara que las razones de la ausencia del Bund eran incidentales y que esperaban que se incorporaran luego (Poslednie Izvestiia 1903b). En el mismo artículo, planteaban la posición de que el próximo Congreso del RSDRP debía ser considerado como un Congreso fundacional del partido, dada la falta de funcionamiento centralizado desde el primer Congreso; y que al mismo debían invitarse representantes de todas las nacionalidades de Rusia (Poslednie Izvestiia 1903b: 321).

Lenin rechazó la acusación del Bund en relación a las maniobras para evitar su participación, y planteó que la declaración sobre las nacionalidades de Rusia, en el sentido de incorporar nuevas organizaciones, dependía, en primer lugar, de que se logre la consolidación de un núcleo sólido de partido a partir de las organizaciones participantes, que pudiera después ampliarse hacia otras organizaciones; esto, a su vez, dependía del éxito del Comité Organizador, al que el Bund no hacía más que ponerle "palos en la rueda". También denunciaba que esta polémica tenía el objetivo de plantear una relación federativa entre el Bund y el RSDRP (Lenin 1903a). En un nuevo artículo, Lenin criticó, a su vez, el anterior artículo de Poslednie Izvestiia, en particular el planteo de que el Bund era una organización independiente del proletariado judío. Contraponía esta "independencia" federativa, con la "autonomía" planteada en el Primer Congreso del RSDRP:

La "autonomía" instituida en los estatutos de 1898 asegura al movimiento obrero judío todo lo que este puede requerir: propaganda y agitación en Yiddish, literatura y congresos propios, el derecho a plantear sus propias reivindicaciones especiales, que serán incluidas en un solo programa socialdemócrata general (Lenin 1903b: 359-360).

Lenin complementó sus posiciones sobre estos planteos del Bund con una discusión más general sobre el problema nacional, defendiendo la consigna a favor de la auto determinación nacional como parte fundamental del programa del partido:

En nuestro proyecto de programa del partido formulamos la reivindicación de una república con una Constitución democrática, que asegure, entre otras cosas, "el reconocimiento del derecho de autodeterminación a todas las naciones que formen parte del Estado" (...) Pero el reconocimiento incondicional de la libertad de autodeterminación no nos obliga en absoluto a apoyar todas las exigencias de autodeterminación nacional (...) Debemos aspirar, siempre e incondicionalmente, a la más estrecha unificación del proletariado de todas las nacionalidades (...) La 
maldita historia de la autocracia zarista nos ha dejado como herencia el enorme distanciamiento entre los obreros de diferentes nacionalidades, oprimidos por esta autocracia (...) no debemos tratar de justificar este mal, de santificar esta anomalía con ningún tipo de "principios" acerca de la singularidad o el carácter "federativo" de los partidos. Lo más simple y lo más fácil, por supuesto, es seguir la línea de la interior resistencia, meterse cada cual en su rincón, de acuerdo con la regla de "'eso no me incumbe a mí", como trata de hacer ahora el Bund (Lenin 1903c: 480-91).

En esta disputa, el planteo de un partido unificado nacionalmente tendía a amalgamarse con la posición a favor de la auto-determinación nacional, mientras que la posición del Bund a favor de la autonomía nacional cultural tendió a cristalizar en una posición federalista en relación a la organización partidaria. Así, el Vto Congreso aprobó una serie de resoluciones dirigidas al próximo Congreso del RSDRP sobre este punto:

Artículo 2. El Bund es la organización Social Demócrata del proletariado judío, no restringida en su actividad por ningún límite geográfico, y entra al partido como único representante del proletariado judío (...)

Artículo 4. El programa del Bund es el programa común al conjunto del partido, al cual tiene el derecho de suplementar en las cuestiones emergentes de la posición especial del proletariado judío en Rusia y la interrelación de fuerzas sociales en el seno de la nación judía, a través de puntos especiales que no sean contrarios al programa común (...)

Artículo 8. El Bund tiene el derecho publicar sin limitaciones, tanto en Yiddish como en otras lenguas. El Bund tiene el derecho de dirigirse al proletariado de otras nacionalidades sólo con el acuerdo de los órganos de las correspondientes secciones del Partido (...). Otras secciones del partido tienen el derecho de dirigirse al proletariado judío sólo con el acuerdo del Comité Central del Bund.

Artículo 11. En caso de necesidad el CC del Partido tiene el derecho de lidiar directamente con secciones particulares del Bund, pero sólo con la aceptación del CC del Bund (...).

Artículo 12. Todos estos puntos deben ser considerados fundamentales y sólo pueden ser cambiados, incorporarse agregados o ser cancelados por mutuo acuerdo entre las secciones del partido (Pearce 1978: 76).

\section{Los debates del Congreso}

Bajo estas circunstancias se efectuó el Segundo Congreso del RSDRP en 1903. El Congreso estuvo marcado por una fuerte disputa interna. En primer lugar, uno de los debates más importantes fue sobre el procedimiento y la inclusión de los distintos grupos que habían enviado delegados, lo que sirvió de preludio a la discusión sobre el estatus del

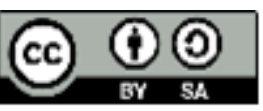


Bund en el partido (Pearce 1978: Sesiones 1 a 3).

Al comenzar el 4to día del Congreso, Liber $^{10}$ introduciría la posición del Bund:

\begin{abstract}
¿Por qué necesitamos una organización para el proletariado judío? Podría ser justificado, en primer lugar, por aquellas condiciones legales particularmente duras bajo las cuales vive la totalidad del proletariado judío, más allá de qué lengua hable; en segundo lugar, por el hecho de que la relación de fuerzas sociales en la nación judía es muy particular, en la cual, por ejemplo, no hay nobles, ni terratenientes, ni campesinos. Y por esta razón cualquier idea de transformar el Bund en una organización territorial (por no hablar del hecho de que estamos en general contra las organizaciones territoriales, dado que llevan a la descentralización) no tiene sentido (Pearce 1978: 77).
\end{abstract}

Liber no consideraba el asunto del lenguaje como un justificativo fuerte para la autonomía, al ser un asunto "puramente técnico". En términos organizativos concretos la propuesta implicaba que el partido se divida en dos conjuntos de secciones locales distintas: una perteneciente al partido en general, y la otra al Bund:

\begin{abstract}
¿Cuál debería ser la relación entre las diferentes secciones del Partido? Yo digo que debería estar basada en el principio de la federación. Una sección del partido debería representar la totalidad de los comités rusos, mientras que la otra debería ser el Bund, organizado como una Unión separada. Usualmente se objeta que estas dos secciones son desiguales, inconmensurables, y por tanto su unificación sobre la base de principios federales sería extremadamente difícil de arreglar. En Austria, sin embargo, ha sido muy posible formar una unión federal de organizaciones nacionales Social Demócratas bajo un principio de igualdad (...) Nuestros oponentes piensan que la federación y la descentralización son sinónimos. Esto no es así. En nuestra visión no hay forma más alta de centralización que la federación (Pearce 1978: 79).
\end{abstract}

Numerosos delegados del Cáucaso intervinieron cuestionando centralmente este aspecto, al igual que Martov. En particular los delegados del Cáucaso enfatizaron como en sus organizaciones locales se agrupaban obreros de todas las nacionalidades del lugar (Pearce 1978: Sección 4).

A su vez, Lenin atacó directamente la idea de una organización federal:

\footnotetext{
${ }^{10}$ Marc Liber (1880-1937): Formó parte del Comité Central del Bund. En 1908 comenzó a dar clases en las escuelas de la organización. Tuvo fuertes vínculos con el RSDRP, teniendo cercanía con el sector de los Mencheviques.
}

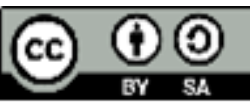


La federación es nociva porque legitima la segregación y el aislamiento, los eleva a la categoría de principio, los convierte en ley. Es verdad que existe entre nosotros un aislamiento total, pero lo que hace falta (...) [es] luchar contra él, reconocer y declarar con decisión la necesidad de marchar firmemente y sin flaquear hacia la más estrecha unidad. Por eso rechazamos por principio (...) la federación, por eso rechazamos cualquier barrera obligatoria que sirva para dividirnos (...) ¿iAcaso no es evidente que el centralismo exige la ausencia de toda barrera entre el centro y los sectores más alejados, más remotos del partido!? (Lenin 1903d: 527).

La resolución que finalmente se adopta en el Congreso fue el absoluto rechazo a federalizar el RSDRP. Ante esto, los delegados del Bund abandonaron el Congreso y el RSDRP. Sin embargo, "antes de que abandonen el Segundo Congreso, los delegados bundistas fueron capaces de introducir algunas modificaciones sobre la cuestión nacional en las resoluciones del RSDRP" (Gechtman, 2008:41), en las cuales se incluyó el siguiente párrafo, que planteaba: "el derecho de la población a recibir instrucción en su idioma vernáculo, el derecho de todo ciudadano a hablar su lengua materna en las reuniones y en las instituciones estatales y sociales." (Lenin1903e: 535).

La lucha del Bund por un nuevo modelo organizativo, adolecía de un problema fundamental: pretendía organizarse como una sección nacional autónoma, al estilo del partido austríaco, en un país donde predominaban las organizaciones locales y generales multinacionales, estructuradas en un partido único. Así, su argumentación en el Congreso debió valerse de argumentos sobre la especificidad del estatus nacional judío que no resultaron convincentes, y abroquelaron al conjunto de los delegados en un repudio al Bund cuya causa principal, a partir del análisis que hacemos de las minutas del Congreso, fue el rechazo a la división de las organizaciones locales Social Demócratas y al solapamiento de organizaciones locales separadas del Bund con otras pertenecientes al conjunto del Partido. Esto unificó a delegados que terminarían estando en veredas opuestas en otros debates del Congreso, tal como Lenin y Martov.

Luego del debate sobre el lugar del Bund en el partido, el Congreso presenció la división del grupo de Iskra, que daría origen a las fracciones bolchevique y menchevique. La causa inmediata de la división fue un debate sobre los estatutos, en la parte que definía quien era un miembro del partido: Lenin presionó por una definición que implicara que los miembros debieran pertenecer a una organización de partido reconocida por el Comité Central, mientras Martov sostuvo una definición que implicaba que era miembro quien adhiriera a su programa y cotizara para el partido. Si tradicionalmente se ha interpretado esto como la confrontación de dos modelos de partido (uno más fuertemente centralizado y de cuadros, y otro de masas y laxo) una nueva interpretación, más ajustada a la evidencia en nuestra

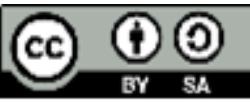


opinión, subraya que la causa fundamental detrás del planteo de Martov era permitir que organizaciones locales como Iuzhni Rabochi (Obrero del Sur), los partidarios de Rabocheie Dielo (Causa Obrera) y los "economistas" de la "Unión de socialdemócratas rusos en el extranjero" no tuvieran que disolverse en organizaciones oficialmente reconocidas; es decir, que tuvieran el derecho a mantener organizaciones preexistentes que pudieran solaparse con las organizaciones oficiales. Martov buscaba evitar escisiones y acumular apoyo para un rol de liderazgo, para lo cual estaba dispuesto a defender el derecho de estos grupos a no fusionarse con las organizaciones oficiales (Mullin 2015: 1-54).

Este planteo podría haberse aplicado al Bund también, que en principio podría haber sido más proclive a esta forma de organización; sin embargo, Martov se había opuesto al estatus del Bund como organización nacional autónoma, y los delegados del Bund se habían retirado al término de este debate en el Congreso. Martov parecía más dispuesto a aceptar la autonomía de ciertas organizaciones por motivos ideológicos y de preexistencia, pero no a aceptar un estatus especial para el Bund por motivos de distinción nacional. De alguna manera, esto resultó poco estratégico para su proyecto organizativo: si hubiera logrado el apoyo de los delegados del Bund, habría amasado una mayoría en el Congreso en relación al problema organizativo.

Después del Congreso, Lenin siguió publicando artículos contra la propuesta federalista del Bund (Lenin 1903f). A su vez, Lenin tomó posición sobre el estatus nacional de los judíos, a favor del asimilacionismo:

esta idea sionista es totalmente falsa (...)"Los judíos han dejado de ser una nación, la cual no puede concebirse sin determinado territorio", dice uno de los más destacados teóricos del marxismo, Karl Kautsky (...) Y estudiando recientemente el problema de las nacionalidades en Austria, este mismo autor procura dar una definición científica del concepto de nacionalidad, y establece dos criterios fundamentales: la lengua y el territorio (...)La idea de una nacionalidad judía se halla en contradicción con los intereses del proletariado judío, pues provoca en él, directa o indirectamente, un estado de ánimo hostil a la asimilación, el estado de ánimo del "ghetto" (...)La hostilidad hacia las capas no nativas de la población sólo podrá ser eliminada cuando estas capas de la población dejen de ser extrañas y se fundan con la masa general de la población. Es esta la única solución posible del problema judio (...) (Lenin1903g:108-12).

\section{De la escisión del Bund a la reunificación con el RSDRP (1903 - 1906)}

A pesar de la salida del Bund del RSDRP, su disputa con Lenin no cesó. Numerosos artículos publicados tanto en Iskra como en Arbeiterstimme pueden dar cuenta de ello. No obstante en el período que corre de 1903 a 1905 el Bund había conseguido posicionarse 
como una de las organizaciones de trabajadores más grandes de Rusia, llegando a alcanzar 30.000 miembros (Zimmerman 2004: 192). Este crecimiento expandió enormemente a partir del estallido de la Revolución Rusa de 1905. La manifestación pacífica que comenzó el 5 de enero en San Petersburgo fue acompañada por una agitación política y económica que llevó a que miles de obreros se movilicen a través de la participación en huelgas y motines. Es por esto que la gran mayoría de los partidos acrecentaron sus miembros, y el Bund no fue la excepción. Sin embargo, la Revolución de 1905 también permitió la consolidación del movimiento sionista y el reflorecimiento de la cultura judía que se expresó en "el rápido crecimiento de la prensa diaria en Yiddish, y en la emergencia de un consenso entre los partidos políticos de judíos a favor del derecho a la autonomía" (Zimmerman 2004: 228-9). Dentro de las organizaciones social-Sionistas que se gestaron en esta época, adquirieron relevancia tres de ellas: la primera, surgió en 1905 bajo el nombre de Partido de Trabajadores Socialistas Sionistas (SS), de orientación territorialista, fue una de las organizaciones judías más grandes después del Bund. Su principal demanda era solucionar el problema territorial de los judíos, aunque no necesariamente en Palestina. En esta línea, enfatizó una orientación hacia el Yiddish - antes que hacia el hebreo-. Otro partido Sionista que emergió en 1906 fue el Partido de Trabajadores Socialistas Judíos (SERP), de orientación autonomista, ponía en primer lugar la lucha por la autonomía nacional de los judíos en Rusia, posponiendo las definiciones sobre la cuestión territorial y Palestina para cuando existiera un Parlamento Nacional Judío en Rusia. En ese mismo año, se formó un tercer partido sionista llamado Partido Social Demócrata de Trabajadores Judíos - Poale Zion. Su principal objetivo era conseguir la autonomía territorial de los Judíos en las tierras de Palestina (Zimmerman 2004: 230). El crecimiento de las organizaciones "socialistas sionistas" implicó una pérdida de hegemonía del Bund en el seno del proletariado judío (Zimmerman 2004: 229).

Hacia el interior del Bund, se había generado un proceso de unificación de las distintas tendencias sobre la cuestión nacional. En ese contexto fue Vladimir Medem ${ }^{11}$ quien más desarrollaría una posición explícita sobre el tema. Sostenía que la Social Democracia debía mantenerse "neutral" en la discusión sobre la cuestión del futuro de la cultura judía, lo que implicaba oponerse a la imposición de la cultura dominante sobre la minoría judía (Zimmerman 2004: 249). Al mismo tiempo, proponía que el Bund adopte el programa de autonomía nacional-cultural como principal demanda política de las clases trabajadores de las nacionalidades oprimidas. El argumento principal que sostenía era que para impedir la opresión nacional, la lucha por la igualdad por los derechos civiles no era suficiente, sino que debía ser acompañada por leyes garanticen el libre desarrollo de todas las culturas a partir del derecho a usar su propia lengua en las instituciones públicas (escuelas,

\footnotetext{
${ }^{11}$ Vladimir Medem (1879 - 1923): Intelectual del Bund, uno de sus teóricos más importantes sobre la cuestión nacional.
} 
parlamento, reuniones públicas). Finalmente, este principio se adoptó como política oficial del Bund, incorporándose a su programa en 1905 en el marco del Sexto Congreso de la organización, que planteaba: la lucha por la igualdad civil; el derecho de usar la lengua nativa en las Cortes e instituciones públicas; y, por último, la autonomía nacional-cultural (Zimmerman 2004: 206).

Mientras tanto, al interior del RSDRP las diferencias entre los bolcheviques y los mencheviques se agudizaron; los mencheviques fueron corriendo a los bolcheviques paulatinamente de los organismos de dirección. Ante esta situación, los bolcheviques llamaron a un nuevo Congreso partidario en 1905, al que asistieron en soledad, reafirmando una escisión de hecho entre las facciones (Mullin 2015: 51-54).

El estallido de la Revolución llevó a que se plantee la necesidad de una reunificación del RSDRP mediante la aceptación de los mencheviques de las reformas de los estatutos adoptadas en el Segundo Congreso. Finalmente eso ocurrió en el Congreso de unificación que se llevó a cabo en Estocolmo en 1906, cuando había comenzado una fuerte avanzada represiva por parte del gobierno de Rusia. La reunificación implicó también la readmisión del Bund al interior del partido, renunciando (más de palabra que de hecho) a la idea de la organización federativa del mismo:

Recientemente se ha celebrado el VII Congreso del Bund (...) Según los informes de este Congreso, el número total de miembros del Bund asciende a 33.000, agrupados en 257 organizaciones. (...) Representantes del Comité Central del Bund se han incorporado al CC del RSDRP (...) (Lenin 1906a: 200).

Creemos que dentro de las razones que llevaron al Bund a reincorporarse al RSDRP, incluso cuando eso significó someterse a los estatutos votados en el II Congreso, tenía que ver con la situación que había generado la Revolución de una relativa pérdida de poder del Bund en el seno del proletariado judío ante la emergencia de las organizaciones sionistas y la necesidad de afianzar alianzas con otras organizaciones socialistas contra el sionismo. En este marco, el Bund se plantea continuar con medidas de acción revolucionaria, entroncando más con la posición de los bolcheviques, tal como fue reconocido por Lenin:

El VII Congreso del Bund estableció los lineamientos generales de nuestra táctica. Ésta consiste en lo siguiente: la disolución de la Duma ha demostrado nítidamente a amplios sectores de la población que es imposible conquistar la tierra y la libertad por la vía pacífica, y que la única salida es la insurrección armada. Lo cual no significa, ni mucho menos, que las elecciones a la nueva Duma impliquen un cambio de la táctica revolucionaria (...) Nuestra tarea en las 
elecciones consiste en (...) convertir las propias elecciones en palestra para la movilización de las masas revolucionarias del pueblo (Lenin 1906b: 410).

\section{Hacia la Primera Guerra Mundial (1907-1914)}

A partir de 1907 el gobierno Zarista busca terminar con las organizaciones socialistas a través de una avanzada fuertemente represiva, y restablecerse en el poder. En este marco todos los partidos sufren un retroceso muy grande a causa de la represión a los activistas. Particularmente, el Bund se ve fuertemente atacado: el gobierno cerró la prensa legal en Yiddish, Folkstsaytung, que había comenzado a circular con la Revolución, y muchos de sus miembros emigraron o se retiraron de las actividades del partido: "mientras que a la altura de la revolución en 1906, el Bund representaba a 274 organizaciones locales en Rusia y a una membresía de 33.890 personas, sólo 10 organizaciones locales estaban representadas en la conferencia del partido en 1910 con un total de no más de 2.000 miembros" (Zimmerman 2004: 227).

Al mismo tiempo, al interior del RSDRP las tensiones entre las diferentes fracciones se intensificaron a raíz de que los mencheviques propusieron un cambio en la táctica del partido con el objetivo de reducir las pérdidas al mínimo: propusieron abandonar las actividades clandestinas e intensificar las acciones legales, uniéndose con los partidos de la burguesía liberal para ganar espacio en el parlamento. Por su parte, Lenin va a llamar a esa tendencia como "liquidacionista" (Broué 1973: 22). En este escenario, emerge Trotsky con un planteo de reunificación de todas las tendencias -incluyendo a los liquidacionistas-, que logra efectuarse en una sesión plenaria del Comité Central en 1910. La unidad también significó la unificación de la prensa del RSDRP en el Social-Demócrata, que fue dirigido por representantes de la tendencia bolchevique y menchevique (Broué 1973: 23).

El debate sobre la legalidad o ilegalidad de las acciones de los partidos, se replicó al interior del Bund, que se inclinó por la posición legalista (Zimmerman 2004: 236). La decisión del Bund estaba relacionada con el reflorecimiento de la cultura judía y de la literatura en Yiddish que había propiciado la Revolución. Desde 1906 en la Zona de Asentamiento habían surgido muchas organizaciones culturales de judíos donde el Bund había comenzado a tener inserción: la Sociedad Literaria Judía, la Sección Yiddish de la Universidad Popular en Varsovia, la sociedad de música dramática en Łódź, y las escuelas nocturnas para judíos adultos en Vilna y Varsovia (Zimmerman 2004: 239-41). El objetivo era enfatizar la lucha por el reconocimiento del Yiddish y educar a la población judía en su lengua materna. Esto último estaba vinculado a las teorías sobre "educación nacional" de Frumkim $^{12}$, quien planteaba la creación de escuelas modernas que eduquen sólo en Yiddish,

\footnotetext{
${ }^{12}$ Esther Frumkin (1880 - 1943): Fue la creadora de la teoría de la "educación nacional". Adoptó un rol importante en la definición ideológica del partido en la época de reflorecimiento de la cultura Yiddish.
} 
como parte del programa de la autonomía nacional-cultural. A su vez pensaba que este tipo de educación, llevada adelante desde una postura socialista, fortalecía la consciencia de clase de los jóvenes judíos de clase trabajadora (Zimmerman 2004: 247).

Este giro político e ideológico del Bund despertó algunos cuestionamientos vinculados a la cuestión nacional, que se pusieron de manifiesto a partir de una serie de publicaciones de algunos activistas del partido que discutían con el "neutralismo" planteado por Medem. Un ejemplo es la nota que escribió y publicó Frumkin en 1908, donde se preguntaba: “¿cómo puede un partido ser oficialmente "neutral" sobre la cuestión del futuro de la lengua y la cultura Yiddish, o sobre el futuro del pueblo judío, cuando está activamente promoviendo la cultura nacional?" (Zimmerman 2004: 249). Esto puso de manifiesto la necesidad de una nueva conferencia, la cual tuvo lugar en 1910 en Lemberg. La decisión de mayor relevancia de la Octava Conferencia manifestaba que si bien el objetivo del Bund era alcanzar la autonomía cultural-nacional del pueblo judío, bajo el estado actual de las cosas, era necesario plantearse una serie de reivindicaciones, que estaban vinculados a la lucha por el reconocimiento y los derechos del Yiddish: abolir cualquier tipo de limitación a hablar en la lengua materna de cada grupo nacional en espacios públicos, y establecer escuelas estatales de cada grupo donde se enseñe en el idioma de cada nacionalidad (Zimmerman 2004: 251), adoptando una posición claramente anti-asimilacionista:

La sociedad de Rusia y Polonia (...) [y] las masas populares de todas las naciones deberían saber que el pueblo judío se esfuerza por una existencia cultural independiente; que ellos no pueden ser "rusificados" o "polonizados"; que ellos necesitan escuelas de Judíos en las que la lengua Yiddish sea reconocida igualitariamente (Di shtime fun buns, No 3, 1910, citado en Zimmerman 2004: 252).

En 1910 también comienza a darse un proceso de intensificación y restablecimiento del movimiento obrero en Rusia. A partir de entonces, las diferencias entre fracciones no hacen más que agudizarse, llegando incluso a una nueva escisión que se puso de manifiesto en la Conferencia en Praga en 1912, a la que acuden los bolcheviques y los "mencheviques del partido", una fracción cuyo referente era Plejánov ${ }^{13}$. En la Conferencia se "expulsa a los liquidadores y se recomienda la creación de "núcleos social-demócratas ilegales rodeados de una red tan extensa como sea posible de asociaciones obreras legales" (Broué 1973: 24). A raíz de esto, Trotsky convoca a una conferencia en Viena con el objetivo de lograr la

Representó al Bund en la Conferencia Lingüística en Chernowitz en 1908, donde se definió al Yiddish como la lengua nacional de los judíos. (Zimmerman 2004: 232).

${ }^{13}$ Georgi Plejánov (1856 - 1918): Principal teórico de la Social Democracia rusa en sus primeros años.

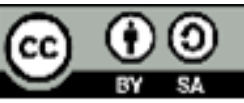


reunificación partidaria; los bolcheviques y los mencheviques del partido se ausentaron de ella. No obstante, los sectores que participaron (entre los que se encontraban los mencheviques) conformaron el llamado 'Bloque de Agosto', el cual se opondría a los bolcheviques. En la Conferencia de Viena se aceptó "la visión de los delegados de la Social Democracia Caucásica, que afirmaban que la autonomía nacional-cultural no contradecía el 'preciso significado' del artículo 9 de programa del RSDRP aprobado en el Congreso de 1903 (que planteaba la fórmula del derecho a la autodeterminación nacional)" (Gechtman, 2008: 43). Ante este hecho, Lenin retomó su polémica contra el programa de la autonomía nacional cultural:

Rusia es un país heterogéneo en lo que a las nacionalidades se refiere. La política gubernamental, que es una política de los terratenientes apoyados por la burguesía, está impregnada de nacionalismo centurionegrista (...) Y junto a esto tenemos el nacionalismo burgués de otras naciones (polaca, judía, ucrania, georgiana, etc.), que está levantando cabeza y pretende desviar a la clase obrera de sus grandes tareas de alcance mundial, orientándola hacia una lucha nacional o una lucha por la cultura nacional. El problema nacional debe ser considerado y resuelto con claridad por todos los obreros con conciencia de clase (...) Los obreros con conciencia de clase son partidarios de la total unidad entre los obreros de todas las nacionales, de todas las organizaciones obreras de cualquier tipo: culturales, sindicales, políticas, etc. (...) Los obreros no permitirán que se los divida mediante discursos empalagosos sobre la cultura nacional o la "autonomía cultural" (...) Los obreros de todo el mundo están creando su propia cultura internacionalista que han venido preparando hace mucho los defensores de la libertad y los enemigos de la opresión" (Lenin 1913a: 293-4).

Lenin continuó su crítica al Bund planteando que habían ignorado deliberadamente resoluciones sobre la unidad a nivel local de las organizaciones Social Demócrata que se habían aprobado en 1906 y confirmado en 1908 (Lenin 1913b). También destacó que incluso "el menchevique neutral Plejanov" había reconocido que la aceptación oficial del programa de la autonomía nacional-cultural implicaba una concesión al nacionalismo (Lenin 1913c). Lenin también atacó la idea de escuelas judías separadas que venía desarrollando el Bund:

La manifestación extrema del nacionalismo contemporáneo es la nacionalización de las escuelas judías (...) ¿qué significa esa nacionalización? Significa aislar a los judíos en escuelas judías (...) el rasgo más pernicioso es el esfuerzo por atizar las llamas del nacionalismo, por aislar una nacionalidad de otra dentro del Estado (Lenin 1913d: 55-6).

Lenin consideraba la posición sobre las escuelas separadas por nacionalidad como "la esencia" del plan de la autonomía cultural nacional (Lenin 1913f: 262). En medio de estos

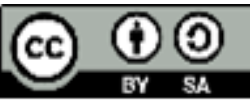


debates, una reunión del Comité Central en el verano de 1913 aprobó unas tesis que confirmaban y precisaban la posición enunciada por Lenin en sus artículos:

1) En la medida en que es de alguna manera posible la paz nacional en una sociedad capitalista basada en la explotación, el lucro y la discordia, dicho objetivo sólo es accesible bajo un sistema de gobierno republicano consecuente y profundamente democrático, que garantice la plena igualdad de todas las naciones e idiomas, que no reconozca un idioma oficial obligatorio, proporcione a la población escuela en las que se enseñe en todos los idiomas nativos; y cuya constitución incluya una ley fundamental que prohíba todos los privilegios de cualquier nación y toda violación de los derechos de una minoría nacional. (...) 3) Los intereses de la clase obrera exigen la fusión de los obreros de todas las nacionalidades de un Estado en organizaciones proletarias unidas: políticas, sindicales, cooperativas, educativas, etc. (...) 4) Por lo que se refiere al derecho a la autodeterminación de las naciones oprimidas por la monarquía zarista, es decir, el derecho a separarse y formar Estados independientes, el Partido Social Demócrata debe indiscutiblemente apoyar este derecho. (...) 5) El derecho de las naciones a la autodeterminación (...) no debe ser confundido bajo ninguna circunstancia con la conveniencia de que se separe determinada nación. El Partido socialdemócrata debe decidir esta última cuestión en cada caso particular de modo absolutamente independiente (Lenin 1913e: 184-5).

\section{Segunda Parte: Polonia}

\section{Los orígenes (1892-1895)}

La declinación del movimiento revolucionario ruso, dominado por los populistas, hacia 1880; junto con el avance de la industrialización en Polonia, generaron las condiciones para el desarrollo de organizaciones socialistas específicamente polacas. Las principales, se reunieron en un Congreso en el exilio, en París en 1892, con el objetivo de organizar un partido socialista unificado. Allí, se aprobó un programa para el Partido que situaba la lucha por la independencia de Polonia como el objetivo principal, en pos de avanzar hacia una "República Democrática independiente" donde se garantice la "total igualdad de las naciones (...) sobre la base de una federación voluntaria". A su vez, planteaba la intención de extender la actividad del socialismo polaco al conjunto de los territorios de la vieja Mancomunidad Polaco-Lituana, con voluntad de construir una fuerza política unificada con el movimiento socialista ucraniano y lituano. Al mismo tiempo, el Congreso también se expidió sobre la actividad de los Social Demócratas judíos de Vilna, exponiendo "sus

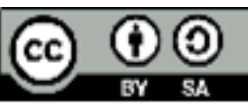


actividades rusificantes como contrarias tanto al interés político de la liberación como a los intereses de la libertad en Rusia" (Zimmerman 2004: 23-4). Por otra parte, los judíos no aparecían mencionados en las resoluciones que aludían a las cuestiones nacionales de Polonia; sí aparecían mencionados en la resolución referente a la lucha por derechos civiles igualitarios para toda la población (Zimmerman 2004: 19-24). En base a este programa, se estableció el Partido Socialista Polaco (PPS) en 1893. El partido le otorgaría centralidad en sus primeros años a denunciar al grupo Social Demócrata de Vilna. En particular, atacaban su uso del idioma ruso en sus encuentros y círculos de estudio; además, le enrostraban al grupo una comprensión distorsionada de la historia polaca, a partir de las visiones de historia polaca que transmitían las escuelas rusas (Zimmerman 2004: 289).

En 1893 se creó la SDKP como reacción al programa nacionalista del PPS, a partir de la convergencia de dos grupos: el grupo de Zürich, de emigrados, conducido por Rosa Luxemburg; y los restos de la Unión de Trabajadores Polacos liderada por Julian Marchlewski $^{14}$ (Blobaum 1992: 207-8). Este grupo se distinguió por su oposición a la independencia polaca, que Luxemburg había justificado por su teoría de que la economía polaca se había integrado orgánicamente en la de las potencias de la partición (la de la Polonia del Congreso, a la de Rusia) y que la demanda de la independencia constituía, en este marco, una concesión al nacionalismo burgués (el desarrollo profundo de esta tesis se expresaría en Luxemburg 1898). Esta posición era acompañada en el terreno práctico por Marchlewski, que en su experiencia de organización había llegado a la conclusión de que agitar por la independencia de Polonia implicaba, por un lado, una invitación a la represión, y, por otro lado, una cuestión que potencialmente podía dividir a la clase trabajadora polaca (de carácter multinacional). El grupo fue dispersado por la represión en 1894: sobreviviría en la emigración y en algunos contactos polacos que reconstruirían una organización años más tarde (Blobaum 1992: 208-9).

En 1893, una serie de reuniones tuvieron lugar en Zúrich entre tres personas judías provenientes de Polonia y Lituania, representando organizaciones y posturas políticas distintas: Luxemburg, por la SDKP; Perl, por el PPS; y Mill, por el Grupo de Vilna. Mill se vio atrapado en la disputa entre los dos grupos polacos. En un primer momento, Luxemburg apoyó la orientación Social Demócrata de Mill contra el PPS (Zimmerman 2004: 54). Pero cuando tomaron consciencia del nuevo giro hacia la agitación de masas y el Yiddish como del Grupo de Vilna, según el relato de Mill (único testimonio de estos contactos), Luxemburg y Jogiches ${ }^{15}$ atacaron su orientación acusando al grupo de ser

\footnotetext{
${ }^{14}$ Julian Marchlewski (1866 - 1925): Fue uno de los fundadores de la Social Democracia del Reino de Polonia y editor del periódico Sprawa Robotnicza, junto con Luxemburg y Jogiches. También militó en la Social Democracia alemana, escribiendo varios trabajos teóricos bajo el apodo "Karski".

${ }^{15}$ Lev Jogiches (1867-1919): Fundador del Grupo de Vilna. Posteriormente, Jogiches abandonó la organización para fundar la SDKP, junto con Luxemburg y Marchlewski.
} 
"100\% separatista, una especie de PPS-ismo en la calle judía". Rechazaban tanto la agitación en idioma Yiddish como una organización judía separada a partir de una visión asimilacionista (Zimmerman 2004: 55).

\section{La clarificación de diferencias (1895-1902)}

Hacia 1895, el Grupo de Vilna extendió su área de influencia hacia Varsovia, donde se superpuso con el área de influencia del PPS. Dos grupos judíos se formaron en Varsovia, cada uno respondiendo a estos dos grupos políticos. El grupo del PPS, dirigido por Róg ${ }^{16}$, era más influyente en un primer momento, e incluso había tomado la delantera en distribuir literatura en Yiddish, imprimiendo el primer folleto en ese idioma destinado al Primero de Mayo de 1895 (Zimmerman 2004: 74).

Apenas se produjo el desembarco de los Litvaks (Lituanos), Róg expresó preocupación por las ventajas que tenían para hacer agitación, y la competencia que suponían para el PPS. El grupo de judíos del PPS le reclamaría varias veces al Partido, entre 1895 y 1897, que incrementara su agitación en Yiddish y formara una sección judía ${ }^{17}$. Como muestra de la fluidez de las fronteras entre los grupos socialistas de la época, el grupo de judíos del PPS reaccionó a su frustración con lo que percibía como un insuficiente interés del liderazgo del PPS por la agitación entre los judíos, formando una unión con el Grupo de Vilna, hacia 1897. La diferencia más importante entre ambos grupos era la cuestión de la Independencia de Polonia; el acuerdo incluyó que los elementos del PPS podían defender la independencia de Polonia en el marco del nuevo grupo, pero la cuestión polaca no sería planteada en reuniones generales ni en la agitación de masas. La fusión se logró en Enero de 1897, adoptando el nombre del "Bund de Trabajadores Judíos de Polonia", pero duraría sólo hasta Mayo del mismo año, debido a que en una reunión de aproximadamente doscientos trabajadores judíos, Róg protestó porque el material del grupo llamaba a los trabajadores judíos a la "unidad del proletariado de todas las naciones", abstractamente, sin plantear la necesidad de una lucha unificada con el proletariado polaco. Esto condujo a un resurgimiento de las discusiones sobre la independencia que finalmente disolvería el grupo, con los elementos que provenían del PPS volviendo individualmente al partido. De esta forma, la presión sobre el Grupo de Vilna llevó a que éste, lejos de aceptar el programa del PPS, fuera definiendo su propio camino, marcado por el vínculo con el movimiento revolucionario ruso y la idea de una organización judía separada (Zimmerman 2004:82).

\footnotetext{
${ }^{16}$ Kazimierz Róg (1873-1933): Fue un banquero judío asimilado a la nación polaca. Participó activamente de los círculos revolucionarios del país antes de la fundación del PPS. Posteriormente fue líder de la sección judía del PPS .

${ }^{17}$ El reproche no era enteramente justo: el PPS había ingresado de contrabando crecientes cantidades de materiales en Yiddish de 1893 a 1896, con cierto retroceso el año siguiente (Zimmerman 2004: 76)
} 
En cuanto a la relación del Grupo de Vilna con la SDKP, más allá de sus diferencias iniciales, Mill estableció canales de colaboración con Luxemburg y Jogiches, sus líderes en el exilio. Mill y sus camaradas apreciaban la capacidad de escritura de Luxemburg y las habilidades conspirativas de Jogiches. A partir de los lazos de colaboración, éstos últimos pudieron ingresar materiales al Imperio Ruso.

Entre 1895 y 1897 cierta cantidad de material de la SDKP fue distribuido a través de canales del [proto] Bund. Cualesquiera fueran las diferencias entre la SDKP y el emergente liderazgo del Bund, estos últimos preferían colaborar con Jogiches y Luxemburg antes que con el PPS. Los términos de Jogiches fueron rígidos: insistió en manejar su propia distribución y finalmente el grupo de Vilna accedió a regañadientes a actuar prácticamente como sus agentes. Esta situación continuó hasta 1897 cuando la creación formal del Bund cerró este conveniente canal de distribución para Jogiches (Nettl 1966: 83).

El conflicto con el PPS parece haber sido uno de los factores que llevó a los miembros del grupo de Vilna a dar el paso de formar un partido propio, el Bund:

Para competir con el PPS (...) necesitábamos el poder y la autoridad de un partido socialista judío, centralizado y disciplinado (...) era esencial para nosotros tener un partido que tomara una posición sin ambigüedades sobre problemas políticos y nacionales difíciles así como sobre (...) la independencia de Polonia (Mill citado en Zimmerman 2004: 84).

La fundación del Bund en 1897, llevó a una nueva seria de polémicas entre este grupo y el PPS. El Cuarto Congreso del PPS, reunido apenas un mes después de la formación del Bund, condenó la formación del grupo, acusando al Bund de "renunciar a la solidaridad con la clase trabajadora polaca y lituana en la lucha por la liberación de la ocupación zarista". En similares términos, el Congreso condenó la formación de un grupo Social Demócrata Lituano que agitaba en lengua polaca, llamando a los lituanos a organizarse bajo la bandera del PPS, a la vez que planteaba reconocer la independencia organizativa "de los grupos revolucionarios lituanos (es decir, aquellos que utilizan exclusivamente la lengua lituana en su agitación)". El partido mostraba así su aspiración de tener un rol de liderazgo sobre las organizaciones de todo el territorio polaco y lituano. A su vez, el Congreso aprobó la necesidad de tener un órgano en Yiddish (Zimmerman 2004: 86-89).

El Bund respondió a estos ataques con dos escritos, una breve pieza titulada "Nuestros objetivos" y una larga respuesta directa al PPS. Ambos escritos ya habían sido distribuidos

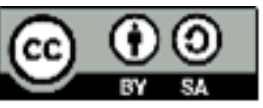


cuando en Julio de 1898 la policía secreta arrestó al conjunto del Comité Central del Bund, su máquina impresora y varias copias de estos materiales y de la prensa del grupo, $D i$ arbeytershtimme. Significativamente, ambos materiales aparecían con el sello del RSDRP (Zimmerman 2004: 92-93). El primer escrito justificaba la necesidad de una organización judía separada, especialmente por la necesidad de agitar en Yiddish y la necesidad de dar una respuesta política particular al anti-Semitismo (Zimmerman 2004: 94). El segundo criticaba al PPS por la siguiente contradicción: arrogarse la exclusividad organizativa sobre los grupos socialistas que hablasen polaco, reconociendo la separación de grupos lituanoparlantes; y a la vez, negarle la independencia organizativa a quienes agitaban en Yiddish. Por último, acusaba a los líderes del PPS de no estar libres del "antisemitismo racial (...) heredado de la arrogante nobleza polaca". Sin embargo, el artículo no planteaba una posición clara sobre "la cuestión polaca" (Zimmerman 2004: 95-98).

En pocos meses después del arresto de casi el conjunto de su dirección, el Bund logró reanudar la publicación de su prensa en Diciembre de 1898, en particular a partir del liderazgo de Mill (que había escapado del arresto por encontrarse fortuitamente en Europa occidental). Mill utilizó el número de la prensa que apareció en Marzo de 1899 para discutir con el PPS, dando una respuesta desde el Bund a la "cuestión polaca". Mill planteaba que no estaba en contra de la independencia de Polonia en principio, pero había un problema de etapas: el derrocamiento del absolutismo tenía que ser la primera prioridad de los socialistas; a su vez, invocaba la autoridad de Kautsky, que había escrito un artículo defendiendo la autonomía nacional en el contexto austríaco (ver la Tercera Parte del presente artículo) para defender la autonomía nacional como el programa nacional socialista, aplicable a la nacionalidad judía (Zimmerman 2004: 107-109). Por el momento, esta autonomía se planteaba en términos vagos y poco definidos.

En el marco de estas disputas con el PPS, el Bund publicó los trabajos de Rosa Luxemburg sobre Polonia, que habían sido discutidos en varios órganos importantes del socialismo internacional en 1899, donde argumentaba su caso en contra de la escisión de Polonia del Imperio Ruso. Aunque Mill agregó una nota despegándose de las opiniones de Luxemburg, el hecho de que difundieran su postura en Yiddish enojó enormemente al PPS (Zimmerman 2004: 113). En 1899 se produce la fusión de la SDKP con dos grupos lituanos, creando la SDKPiL (Nettl 1966: 105). El restablecimiento del partido en la Polonia del Congreso desde 1899 tuvo mucho que ver con la asistencia organizativa del Bund (Kuhn 1998: 15).

Para el 1900 la SDKPiL se había extendido a la mayoría de las grandes ciudades industriales de Polonia y a la zona minera-carbonífera (...), aunque su membresía aún era predominantemente artesanal antes que industrial. Ahora que un partido ruso había llegado a formarse, la SDKPiL (...) comenzó a discutir la posibilidad de fusión (Nettl 1966: 105).

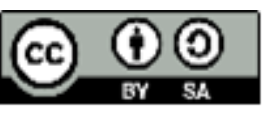




\section{Transformaciones ideológicas y políticas (1902-1904)}

El año 1902 marcaría el comienzo de importantes transformaciones para la posición sobre la cuestión judía del PPS. El Sexto Congreso del partido, en Junio de ese año, volvió a condenar la orientación rusa del Bund. A su vez, rebajó su anterior posición hacia Lituania, llamando a los socialistas lituanos a unirse al PPS como una "sección autónoma". Asimismo, sobre la nacionalidad judía, el congreso planteó que la pregunta sobre si los judíos eran o no una nación en el sentido pleno del término merecía mayor debate; pero que, incluso si fueran una nacionalidad en sí misma, igualmente se debía demandar de ellos "lealtad a los intereses generales del país" (Zimmerman 2004: 169). El Congreso aprobó la creación de un Comité Judío Oficial del partido, que pasó a ser un cuerpo semi-autónomo, responsable de la prensa en Yiddish, con representación en el Comité Central y con sus propias conferencias (Zimmerman 2004: 165).

El líder de esta nueva sección judía sería Feliks Sachs $^{18}$, quien se mudaría a Vilna y comenzaría a proponer una serie de cambios programáticos para el PPS. Sachs haría tres planteos, que en algunos casos serían publicitados directamente en el periódico en Yiddish Der arbeyter, que pasaría a publicarse en Vilna bajo su control. En primer lugar, que el partido debía suavizar su posición sobre Lituania, otorgando autonomía al movimiento socialista de las restantes nacionalidades; en segundo lugar, que los judíos debían ser tratados como una nacionalidad más, justificándose en lo extendido de esa idea en Lituania. En tercer lugar, el partido debía entender las inclinaciones de los Judíos de Lituania, que tras un siglo de dominio ruso habían cultivado cierta simpatía por dicha cultura (Zimmerman 2004: 171-173).

El incremento de la actividad del PPS en Lituania no pasó inadvertido para el Bund. En una serie de artículos en su prensa, Di arbeytershtimme, el Bund propagandizó dos ideas principales en relación al PPS. En primer lugar, el Bund explotaba las divisiones de los distintos grupos socialistas en Polonia para rechazar la demanda de una actividad bajo la bandera del PPS: la existencia de al menos otros tres grupos socialistas en Polonia y Lituania (la SDKPiL, los Social Demócratas Lituanos y un pequeño y efímero desprendimiento del PPS, el PPS-Proletariado) ponía en cuestión la demanda de exclusividad regional del PPS. El Bund destacaba como todos estos grupos tenían posiciones sobre la cuestión polaca que empalmaban con las suyas: la SDKPiL era antiindependentista; los SD Lituanos planteaban una unión federal de Lituania, Polonia y Rusia; el PPS-Proletariado planteaba que la demanda de la independencia debía ser pospuesta hasta la obtención de una constitución en Rusia. Todos estos grupos, a diferencia

\footnotetext{
${ }^{18}$ Feliks Sachs (1869-1935): Se incorporó al PPS, participó de la editorial de Robotnik, y posteriormente, se unió a la editorial del Der arbeyter, debido a que hablaba Yiddish y quería acercar a los trabajadores judíos al partido. Fue uno de los líderes de la Sección Judia de la organización.
}

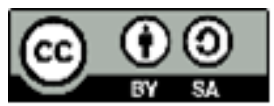


del PPS, reconocían la independencia organizativa del Bund. En segundo lugar, la prensa del Bund sugería que en áreas étnicamente mixtas como las de Europa oriental, los partidos socialistas no podían representar un territorio dado, sino a los trabajadores de una nacionalidad dada (Zimmerman 2004: 174-176). Esto era una apelación directa al modelo austríaco. En tercer lugar, planteaba que la posición del Bund era favorable a la independencia de Polonia en el largo plazo pero no como parte del programa mínimo, sino después de la derrota del absolutismo zarista (Zimmerman 2004: 177).

Paralelamente, las relaciones del Bund con la SDKPiL pasaron por un nuevo período de acercamiento. En términos organizativos las posiciones de la SDKPiL favorecían comités unificados sobre una base territorial de todos los miembros polacos, alemanes y judíos del partido (Kuhn 1998:14). No obstante, sus relaciones generales con el Bund tendieron a ser amigables. En este período, la SDKPiL enfatizó su lucha contra el antisemitismo:

El primer número del órgano partidario, Czerwonysztandar, en noviembre de 1902 proclamó que "los trabajadores judíos son nuestros hermanos, son tan proletarios como los trabajadores polacos". Esta defensa de los judíos ganó algunos miembros judíos del PPS a la SDKPiL. Pero el tamaño y la influencia del Bund llevaron a que (...) tuviera una capacidad extremadamente limitada de organizar a trabajadores judíos (Kuhn 1998: 15).

En cuanto al PPS, en Abril de 1903 se reunió por primera vez la Conferencia de la Sección Judía del Partido, encabezada por Felix Sachs. En donde se discutió, como uno de sus puntos principales, la relación con el Bund y la posibilidad de hacer acciones comunes. Se resolvió que dadas las diferencias políticas, era imposible hacer acciones generales comunes; aunque, si se podían hacer acciones comunes limitadas, sobre todo en relación a reivindicaciones económicas (Zimmerman 2004: 179). Esto se llevó a discusión en el Comité Central del Partido, en Junio, donde la discusión adoptó mayor alcance a la hora de considerar la posibilidad o no de aceptar la independencia organizativa del Bund. Se presentaron tres posturas: reconocer incondicionalmente la independencia del Bund (Sachs); reconocerla condicionalmente (Pilsdulski ${ }^{19}$ ); y oponerse a cualquier reconocimiento (posición muy minoritaria). Sachs defendió su visión argumentando que el

\footnotetext{
${ }^{19}$ Józef Pilsudski (1867 - 1935): Nació en una familia noble y nacionalista, en una ciudad cerca de Vilna. En 1893, con el objetivo de luchar por una Polonia libre, ingresó al PPS. Al poco tiempo, comenzó a formar parte del Comité Central y a configurarse como una de las figuras con más influencia dentro del partido. Tuvo un rol central en el desarrollo ideológico del mismo en relación a la cuestión nacional. En este sentido, Piłsudski fue uno de los promotores de las discusiones con el Grupo de Vilna, y posteriormente, con el Bund. Ante la división del PPS, Piłsudski lideró el ala nacionalista de derecha.
}

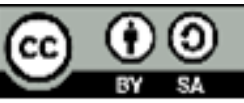


PPS ya no podía mantener la ilusión de poder absorber al Bund (una organización significativamente más grande que el PPS) dentro del partido; el PPS debía entrar en una relación federal con el Bund, tratando de hacerle adoptar su programa. Se resolvió que se redactaría una respuesta conjunta al Bund, ejecutada por Sachs y Pilsdulski. Por otro lado, se debatió la resolución elevada desde la Conferencia de la Sección Judía en favor de la unidad de acción limitada con el Bund; Pilsdulski planteó que debía ser aprobada con el limitante de que se aplicaría únicamente a Lituania (Zimmerman 2004: 179-181). La respuesta planteada al Bund salió poco después, firmada por Sachs. Las líneas argumentativas principales de Sachs fueron: que el Bund en la práctica no agitaba la demanda de la independencia, más allá de su supuesta posición a favor en el largo plazo; que el Bund había entrado al RSDRP y tenía escaso interés en la cuestión nacional. Por último, argumentaba que en la propaganda del Bund existían numerosas referencias de solidaridad con el pueblo ruso, pero no informaban en absoluto a sus lectores ni se posicionaban en torno a la extrema opresión que sufrían los lituanos y polacos (Zimmerman 2004: 181-183).

De esta manera, el Bund, que era acusado de nacionalista en el ambiente de la Social Democracia rusa, era acusado de no abordar suficientemente la cuestión nacional por parte de los socialistas nacionalistas del PPS.

Posteriormente al Segundo Congreso del RSDRP desarrollado en Julio de 1903, donde el Bund se separó de dicho partido, una posición cada vez más conciliadora hacia el Bund tendió a instalarse en el PPS, que también condujo a reevaluaciones sobre la cuestión nacional judía por parte de algunos de sus intelectuales. En Agosto de 1903, un artículo escrito en el periódico del PPS por Kelles-Krauz prometía a los miembros del Bund que el PPS, al contrario que el RSDRP, estaba dispuesto a otorgarle autonomía al Bund; a su vez, planteaba que de acuerdo a las resoluciones del Sexto Congreso del PPS, los Judíos tendrían pleno derecho a crear "escuelas judías y otras instituciones culturales en todo el territorio de una Polonia libre" (Zimmerman 2004: 184-185). Asimismo, consideraba que los judíos claramente eran una nacionalidad moderna "porque la nacionalidad judía está siendo formada bajo el influjo de los mismos factores que han fortalecido o revivido las [nacionalidades] Francesa, Alemana, Italiana, Eslovena (...) la democratización de la cultura, el acceso a bienes culturales por parte del pueblo, que permite a las masas apropiarse y continuar el desarrollo de la cultura" (Kelles-Krauz citado en Snyder 1997: 237). Haciendo un análisis histórico del desarrollo de la nacionalidad judía, Kelles-Krauz planteaba que la mayoría de los judíos permanecería en Europa Oriental, donde la asimilación judía no se daría en el futuro cercano. Por tanto los judíos debían tener derecho a desarrollar el idioma y la cultura Yiddish (Zimmerman 2004: 187-188).

En cuanto a la SDKPiL, ésta intentó una fusión fracasada con el RSDRP, en 1903. El trasfondo de la misma había sido un cuestionamiento por parte de una fracción de la

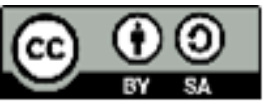


emigración, dirigida por Wojnaroska ${ }^{20}$, que a partir del 1900 había comenzado a tratar de reorientar la línea nacional del partido hacia una posición más flexible en relación a la independencia polaca, y menos agresiva hacia el PPS. Desde ese año, ella representaba al partido ante el Buró Socialista Internacional. Hacia el Congreso de 1903 de la Social Democracia Rusa, el ala más tradicional del Partido, liderada por Luxemburg, atacó la formulación del nuevo programa que planteaba el reconocimiento del derecho a la autodeterminación. Wojnarowska, por el contrario, no tenía nada que objetar a la nueva formulación y condenó a Luxemburg por evitar la unidad con el RSDRP sobre esta base. De a poco, fue corrida de todas sus posiciones de responsabilidad hasta que renunció al partido en 1904 (Blobaum 1992: 210-214).

\section{El período revolucionario (1905-1908)}

El preludio inmediato de la revolución fue la Guerra Ruso-Japonesa. Durante la misma, la Polonia del Congreso entró en una severa crisis económica. Para el otoño de 1904, las industrias de Varsovia despidieron entre un 25 y un $33 \%$ de sus trabajadores, mientras los salarios cayeron entre un 33 y un 50\%. Para Diciembre, la cantidad de desempleados era tan grande que grupos de caridad, judíos y cristianos, estaban manejando comedores para alimentar a los desempleados. Todos los grupos socialistas comenzaron a expandirse liderando la agitación contra la guerra, con una posición derrotista hacia el Imperio Ruso. Para citar algunos ejemplos, en el otoño de 1904, el PPS multiplicó su membresía por cuatro en Varsovia (368 a 1500) y por cinco en Łódź (de a 100 a 500). La membresía del Bund ascendió a 900 en Łódź y a 1200 en Varsovia. La SDKPiL creció de 25 miembros en Łódź a 120 hacia Enero de 1905 (Zimmerman 2004: 193-194).

La llegada del Domingo Sangriento y la Huelga General de Enero y Febrero en Rusia conmocionó profundamente a los partidos socialistas de Polonia. Para el PPS fue el golpe más directo, dado que su programa estaba basado en parte en una falta de confianza en el potencial de los movimientos revolucionarios de Rusia. Por el contrario, la SDKPiL y el Bund tendieron a fortalecerse con este desarrollo. Sin embargo, los tres partidos vacilaron los primeros días. Al poco tiempo, se crearon oportunidades para la acción conjunta que superaron años de luchas fraccionales entre los grupos. Los tres partidos acordaron llamar a una huelga general en Polonia el 28 de Enero; la huelga, sin embargo, comenzó espontáneamente un día antes. Los Comités locales de Varsovia y Łódź del PPS emitieron

\footnotetext{
${ }^{20}$ Cezaryna Wanda Wojnaroska (1861- 1911): Nació en Polonia, en una familia de ascendencia noble. Se involucró en el socialismo polaco y fue arrestada numerosas veces hasta que emigró a Francia, desde donde militó en el movimiento socialista polaco como emigrada, integrándose a la SDKP desde 1893. Entre 1900 y 1904 representó a la SDKPiL en el Buró Socialista Internacional. En la última etapa de su vida se involucró en el socialismo francés.
}

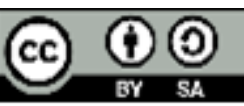


una declaración política que planteaba la lucha por libertades democráticas de reunión, prensa y palaba; igualdad de derechos civiles; y el derecho de los trabajadores a formar sindicatos y hacer huelgas. En lo referente a la cuestión nacional, planteaba el uso de polaco en todas las instituciones públicas, la garantía de un libre desarrollo cultural para "el pueblo judío y otras minorías nacionales" y una nueva demanda: Una asamblea constituyente polaca en Varsovia elegida por sufragio universal. Fue el primer programa en la historia del PPS que vinculaba la liberación nacional polaca con el desarrollo del movimiento revolucionario ruso (Zimmerman 2004: 194-198).

La presión de la revolución provocó una creciente división a la interna del PPS, que tendría consecuencias sobre las posiciones de cada grupo frente a la cuestión judía. La división salió a la luz con más fuerza en un nuevo Congreso partidario, realizado en marzo de 1905 a partir de una convocatoria de los comités locales. Pilsdulski se encontraba en Cracovia. Dos fracciones se enfrentaban: el ala izquierda, también llamada Joven; y la Vieja Guardia, el ala de derecha nacionalista insurreccional. El Congreso reformuló la demanda de la independencia polaca en el sentido ya planteado en Enero: una Asamblea Constituyente en Varsovia, dependiente de la caída del zar, de acuerdo a los lineamientos del ala izquierda. Esto implicaba bajar el tono del separatismo y mostrarse más proclives a la colaboración con otros partidos revolucionarios del Imperio Ruso. A su vez, el partido creó un ala militar. La orientación de la facción Joven dominó todavía más después de un consejo partidario en Junio del mismo año, donde se hizo con el Comité Central y el órgano central del partido; la Vieja Guardia se hizo fuerte en la organización militar del partido (Zimmerman 2004: 198-202).

Hacia el Congreso de Noviembre 1906 ,que consagraría la escisión definitiva del PPS, la Sección Judía (que creció enormemente en esta etapa y en la cual predominaba la facción Joven), propuso un giro hacia la adopción definitiva de un programa de autonomía nacional-cultural para los judíos de Polonia. Un artículo de Horowitz publicado en Kurjercodzienny, el primer diario legal del grupo, marcó las líneas principales para este giro. El PPS demandaba el fin de todas las leyes discriminatorias así como la plena autonomía cultural aplicada a todas las instituciones públicas, escuelas, administración y cortes legales. Horowitz criticó la tendencia intelectual a despreciar el Yiddish como un lenguaje atrasado del ghetto, y afirmó el pleno derecho de los judíos de Europa Oriental a cultivar el Yiddish. Horowitz planteaba que iba en favor de los intereses del proletariado polaco el que sus hermanos de clase judíos pudieran desarrollar su educación y cultura de la manera más directa y efectiva posible. La Sección Judía envió una propuesta programática al Congreso basada en este artículo (Zimmerman 2004: 209-212).

A lo largo de 1906 Pilsdulski removió crecientemente al ala militar del partido del control partidario. Crecientemente se volcó a realizar ataques cada vez más directos a las fuerzas represivas, a medios de transporte, y acciones de expropiación. El Comité central del

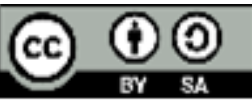


partido llamó a Pilsdulski a centrarse en acciones de autodefensa, lo que fue totalmente ignorado; finalmente llamó a un alto de todas las acciones militares y un Congreso a fines de ese año. En el mismo, se debatió una resolución, escrita por Sachs, que caracterizaba las tácticas militares empleadas como extremadamente divergentes de la línea política general del partido. Como resultado de esto, la Vieja Guardia se separó del partido y formó una nueva organización llamada PPS-Facción Revolucionaria (Zimmerman 2004: 212-213).

La nueva organización realizó su primer Congreso en Marzo de 1907. En el mismo reafirmó el planteo de la independencia de Polonia como el primer punto de su programa mínimo, y un desvío significativo con respecto a la línea de la facción Joven sobre la cuestión judía. Con la dirección de Perl $^{21}$ sobre este punto, incluyó sólo un punto general en su programa que llamaba a una protección de los derechos de las minorías nacionales. No estaba claro que esto incluyera a los judíos, dado que Perl sostenía una política abiertamente asimilacionista en relación a los mismos (Zimmerman 2004: 213-214).

En el marco de las elecciones a la Duma de 1906, los partidos socialistas boicotearon las elecciones. El Partido Nacional Democrático, de derecha, ganó una gran mayoría e impulsó un discurso abiertamente antisemita contra los Demócratas Progresivos, un partido liberal con apoyo de capas medias judías, y los socialistas. En las elecciones a la Segunda Duma, en 1907, el Bund formó una alianza con la SDKPiL, participando por primera vez de elecciones. En un sistema electoral censitario, todos los electores de las tres bancas reservadas a los trabajadores fueron para esta alianza. La Segunda Duma duró sólo unos meses; el golpe de Stolypin cerró el período de la revolución (Zimmerman 2004: 215-219).

Las organizaciones socialistas habían crecido enormemente en este período, deviniendo en organizaciones de masas. Al momento de la escisión el PPS contaba con unos 55000 miembros. La SDKPiL estaba cerca de los 35000 miembros a fines de 1906. El Bund tenía aproximadamente 34000 miembros en el Imperio Ruso, con su organización en la Polonia del Congreso contando con cerca de 5300 miembros. Por otro lado, varias organizaciones no socialistas lograron una base amplia con elementos obreros: el ala obrera de los Nacional Demócratas tenía 23000 miembros; la Asociación de Trabajadores Cristianos tenía 22000 (Zimmerman 2004: 214).

\section{El período de la derrota revolucionaria hasta la Primera Guerra Mundial (1908-1914)}

En este período, todas las organizaciones socialistas de Polonia retrocedieron en membresía, a la vez que clarificaban sus posturas sobre la cuestión judía.

\footnotetext{
${ }^{21}$ Feliks Perl (1871-1927): Proviene de una familia de clase media judía asimilada a la nación polaca. Fue uno de los intelectuales del PPS y editor de Robotnik. Tuvo un rol protagónico dentro del PPS FracciónRevolucionaria.
}

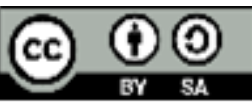


El PPS-facción Revolucionaria, dejaría de tener existencia real en la Polonia del Congreso hacia 1908, pasando a funcionar desde Cracovia y priorizando cada vez más la formación de un ala armada (Zimmerman 2004: 257). Afectado por los conflictos por los que atravesaba su partido hermano en Austria (que veremos a continuación) planteó una postura abiertamente asimilacionista hacia los judíos polacos. Un ejemplo de esto apareció en un artículo publicado en Przedswit, el periódico del partido, donde Perl recurriría a argumentos de Otto Bauer para plantear que los judíos no constituían una nación en el sentido moderno del término y que la demanda de autonomía cultural para ellos sólo prolongaría la separación de los judíos (Zimmerman 2004: 260). La organización no se desviaría de esta postura hasta la Primera Guerra Mundial.

En cuanto al PPS de Izquierda, el partido reconocía el derecho a la autonomía cultural judía. En los años 1909-1910, el partido reaccionó a una nueva oleada de antisemitismo oficial en Polonia, auspiciada por los partidos burgueses, publicando frecuentemente condenas abiertas de este clima en sus órganos partidarios. A su vez, una serie de publicaciones intentaron clarificar sus diferencias con el Bund; las mismas planteaban que, en una situación comparable con el destino del Yiddish en Estados Unidos (donde había florecido como lengua de los migrantes, pero tendía a desaparecer en la segunda generación), el florecimiento del Yiddish en Polonia sería seguramente un fenómeno transitorio; el partido estaba a favor de la asimilación en el mediano plazo, pero no como un proceso forzado (Zimmerman 2004: 268-269).

En cuanto a la SDKPiL, Rosa Luxemburg clarificó sus posiciones sobre la cuestión nacional en general, y la judía en particular, en una serie de artículos publicados en 1908 y 1909. Comentando sobre el programa de la autonomía nacional judía, plantearía lo siguiente:

La autonomía nacional judía, no en el sentido de libertad de escuela, religión, lugar de residencia, y derechos civiles igualitarios, sino en el sentido del autogobierno político de la población judía con su propia legislación y administración (...) es una idea enteramente utópica. Extrañamente, esta convicción prevalece también en el campo de los nacionalistas polacos extremos, en la así llamada "Fracción Revolucionaria" del PPS donde está basada en la simple circunstancia de que la nacionalidad judía no posee "un territorio propio" al interior del Imperio Ruso. Pero la autonomía nacional [está] (...) "en el aire", sin un territorio definido (...).Por otro lado, este desarrollo capitalista no lleva a una separación de la cultura burguesa judía, sino que actúa en una dirección exactamente opuesta, llevando a la asimilación de la burguesía judía y la intelligentsia urbana (...) la distinción nacional judía en Rusia y Polonia está basada en la socialmente retrasada pequeña burguesía, en la pequeña producción, el pequeño comercio, la vida pueblerina y (...) en la estrecha relación de la 
nacionalidad en cuestión a la religión (...) Obviamente, un esfuerzo en el sentido de "desarrollar la cultura judía" por iniciativa de un puñado de publicistas y traductores en Yiddish no puede ser tomada seriamente (Luxemburg 1909: 266267).

Al año siguiente, precisaría su posición en un artículo, planteando que la postura de la SDKPiL era que los judíos progresivos, incluyendo a la clase trabajadora, tarde o temprano adoptarían la cultura polaca. Sin embargo, los judíos no debían ser forzados hacia esa conclusión (Kuhn 1998: 15).

\section{Tercera Parte: Galitzia}

\section{La clase obrera judía en Galitzia}

Galitzia, la provincia polaca del Imperio Austro-Húngaro, era una de sus zonas más atrasadas. Los judíos formaban el $10 \%$ de la pequeña clase obrera de Galitzia (más o menos el mismo porcentaje que ocupaban los judíos con respecto a la población total). Los judíos austríacos estaban formalmente emancipados desde 1867; sin embargo, permanecían como un grupo oprimido, especialmente en esta zona, donde la inmensa mayoría de la población judía tenía al Yiddish como primer lenguaje. Legalmente el Yiddish no era un idioma reconocido, por lo que no tenía el mismo estatus que los demás idiomas en las cortes, ante las autoridades públicas y en el sistema educativo (Kuhn 2011: 47)

\section{El socialismo en Galitzia}

En Galitzia se formó inicialmente un partido socialista regional, que en 1892 adoptó el nombre de Partido Social Demócrata de Galitzia (GPSD). En 1897, la Social Democracia austríaca adoptó el principio de una organización partidaria federal, con partidos autónomos por nacionalidad. En 1899, después de que sus miembros Rutenios (Ucranianos) hubieran formado un partido propio, el partido devino el partido nacional Partido Social Demócrata Polaco de Galitzia (PPSD). En un primer momento, el partido regional, que incluía entre sus miembros a varios intelectuales judíos, tuvo una postura hostil al asimilacionismo. A medida que avanzaba la década de 1890, la postura del partido se fue volcando cada vez más al nacionalismo polaco, con actitudes cada vez más asimilacionistas hacia la población judía. Hacia 1900, la inclusión de judíos en el partido entró en crisis mientras el socialSionismo crecía en Austria; entre 1900 y 1901 se armó una organización sindical Sionista para trabajadores judíos de cuello blanco en Viena (Kuhn 2011: 48).

\section{El intento de armar un Partido Social Demócrata Judío en Galitzia}

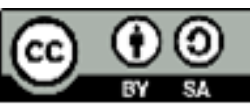


Una nueva camada de activistas universitarios, entre los que estaba Henryk Grossman ${ }^{22}$ en Cracovia, fue fundamental en provocar un renacimiento en las actividades de los socialistas judíos en Galitzia (Kuhn 2011: 49). En 1904, antes del 9no Congreso del PPSD que se celebraría en Octubre-Noviembre del mismo año, un grupo de activistas judíos del partido formó un comité organizativo secreto para preparar un partido judío independiente. En el Congreso, tres miembros del comité presentaron una moción rechazando la actividad del moribundo Comité de Agitación Judío del Partido. La moción criticaba la falta de atención a las publicaciones en Yiddish y la inefectividad en el combate contra la influencia Sionista entre los trabajadores judíos. La moción fue derrotada en el Congreso, el cual condenó la idea de una organización socialista separada. A su vez, en el mismo Congreso se aprobó una moción por la cual el PPSD entraba en una alianza exclusiva con el PPS entre los partidos de la Polonia del Congreso; otra victoria sobre sectores de oposición interna (principalmente judíos) que simpatizaban con el Bund y la SDKPiL (Kuhn 2011: 50).

Grossman publicó un panfleto en Enero de 1905 que llamaba a un partido judío independiente. Su posición era básicamente bundista; criticaba tanto a los asimilacionistas polacos, como a los sionistas; corriente que en su opinión expresaba los intereses de la burguesía judía (Kuhn 2011: 50-51).

En Marzo el liderazgo del partido actuó contra los disidentes judíos, a través de la Central Sindical de Galitzia, controlada por el partido. Esta decidió disolver los sindicatos y asociaciones educativas locales judías. Provocados por la decisión rupturista del partido polaco, los disidentes judíos proclamaron un nuevo partido, el Partido Social Demócrata Judío de Galitzia, (ŻPSD) el 1ero de Mayo de 1905 (Kuhn 2011: 51).

El manifiesto inaugural del partido declaraba el compromiso del mismo con la ortodoxia Social Demócrata de Austria:

No somos nacionalistas, no somos chauvinistas, y nadie ha enfatizado el carácter de clase de nuestra lucha más que nosotros. Nadie ha luchado contra el Sionismo como un movimiento de clase de la burguesía judía más despiadadamente que nosotros. No queremos un programa nacionalista, simplemente queremos una organización nacional (...) Queremos el mismo tipo de organización nacional que los Alemanes, Polacos, Checos, Eslavos del Sur, e incluso los Ucranianos ya tienen en Austria, y que sólo los judíos no tienen! (documento citado en Kuhn 2011: 52).

\footnotetext{
${ }^{22}$ Henryk Grossman (1881- 1950): Nació en Cracovia, en el seno de una familia judía. Polemizó con el Sionismo y el asimilacionismo. Formó parte del PPSD, hasta que se posicionó a favor de la creación de una organización de judíos independiente. Después de la Primera Guerra Mundial militó en el comunismo polaco y adquirió notoriedad por su trabajo sobre la teoría marxista de las crisis (Kuhn, 2011: 24).
} 
Rosa Luxemburg ironizaría sobre la separación de los socialistas judíos de Galitzia de su partido en los siguientes términos:

Finalmente, la última semana nos ha provisto de un fenómeno enteramente característico no desprovisto de un toque de comedia: una confrontación violenta entre el partido de Galitzia y la tendencia separatista de los Socialistas Judíos al interior de la organización polaca. Siguiendo fielmente en los territorios prusianos y rusos, la posición del PPS, cuyo separatismo es públicamente apoyado por los líderes del partido de Galitzia, e incluso usando algunos de los argumentos del PPS, los Social Demócratas Judíos se aíslan del partido del proletariado de Galitzia, y por tanto le dan a quienes apoyan el social patriotismo la oportunidad de ver la otra cara de la moneda: la fragmentación del proletariado como el resultado lógico de su tendencia. Para superar esta tendencia, que ha amenazado su existencia, el partido de Galitzia se refugió en la autoridad de la Social Democracia pan-austríaca, de la cual obtuvieron una condena total de los separatistas, es decir, de los separatistas judíos (Luxemburg 1905: 90).

Luxemburg subrayaba cómo el impulso de organizaciones nacionalmente separadas se le había vuelto en contra a los Social Demócratas Austro-Alemanes.

Poco tiempo después, un activista de la organización, Balakan, escribió un interesante libro en alemán que defendía la política del nuevo partido. A su vez, contenía un penetrante análisis, compartido con el Bund, del carácter del Sionismo, al cual vería como: "El movimiento al interior de la pequeña y mediana burguesía judía, que se encuentra bajo la doble presión de la competencia del gran capital por un lado y las leyes de excepción y el incitamiento del régimen y elementos burgueses de la población cristiana por el otro lado" (Kuhn 2011: 53). A su vez, advertía que los Sionistas tendrían que comprar u obtener por la fuerza tierra en Palestina; criticó la disposición de los sionistas a ponerse al servicio de la política reaccionaria del Sultán otomano, y advirtió que el Sionismo tendría un carácter cada vez más expansionista, incluso por fuera de Palestina (Kuhn 2011: 55).

En julio Grossman escribió un reporte de la actividad del nuevo partido al Bund donde enfatizaba que una de las batallas principales del partido era su lucha contra el Sionismo y específicamente contra Poale Zion. Meses más tarde, escribió una apelación al Congreso General del Partido Pan-Austríaco pidiendo reconsiderar la decisión de su Ejecutivo, que había decidido no reconocer al partido judío. En la misma, volvió a enfatizar la lucha del partido contra el Sionismo y las corrientes judías burguesas (Kuhn 2011: 56-57).

Entre 1905 y 1907 una importante lucha por el sufragio universal, en la que los socialistas tendrían un papel principal, sacudió Austria. Los Social Demócratas Judíos de Galitzia participaron de la lucha, en oposición a los Sionistas que primero la habían boicoteado y después pasaron a reclamar un parlamento dividido por nacionalidades. En las primeras

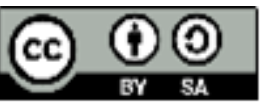


elecciones con sufragio universal, los Social Demócratas judíos hicieron campaña a favor de los candidatos del PPSD y contra los candidatos Sionistas y los candidatos judíos de partidos burgueses (Kuhn 2011: 59).

En 1907, Grossman editó un nuevo panfleto sobre la política de su partido. El mismo contenía una crítica actualizada del Sionismo Socialista, al cual acusaba de ser incapaz de luchar por la democracia aquí y ahora en Austria. A su vez, acusaba al PPSD de haber descuidado el movimiento judío, ayudando que muchos trabajadores judíos fueran seducidos por el Sionismo. El Partido Polaco, en palabras de Grossman, ha "convertido la lucha de clases del proletariado judío en una lucha chauvinista entre dos nacionalismos" (Kuhn 2011: 61). Grossman convertía las circunstancias inmediatas que lo habían empujado a armar una organización nacional en un principio: esta era la única forma de organización posible en Austria desde fines de 1os 1890 (Kuhn 2011: 62). El análisis general de Kuhn es que, de esta manera, se desaprovechó una importante oportunidad de estructurar una corriente política nacionalmente mixta de izquierda que pudiera oponerse a la línea dominante del PPSD, desperdiciando una trayectoria política que incluía muchos contactos con obreros e intelectuales de distintas nacionalidades (Kuhn 2007: 35-73).

En el mismo año, se editó en Austria el influyente trabajo de Otto Bauer, La Cuestión de las Nacionalidades y la Social Democracia. En el marco de un trabajo que argumentaba largamente a favor de una política de luchar por la reforma del Imperio Austro-Húngaro, obteniendo una reorganización del mismo que permitiera el ejercicio de la autonomía cultural de cada nacionalidad, en forma extra territorial, a través de órganos políticos específicos, Bauer negaba que ese planteo se aplicara a los judíos. Su argumento era que los judíos habían claramente conformado una nación en la Edad Media; no obstante, el desarrollo del capitalismo disolvió su rol social como mercaderes y prestamistas, al englobar la economía monetaria el conjunto de la sociedad. Así los judíos estaban dejando de ser una nación, más rápidamente en Europa Occidental y más lentamente en Galitzia y Europa Oriental, que contenía grandes cantidades de judíos pertenecientes a la pequeña burguesía y la clase obrera, con poca educación. La falta de territorio, y la desaparición de su función económica específica, hacían inevitable la asimilación de los judíos. La adquisición de instituciones culturales judías propias, sólo incrementaría el sufrimiento de la población judía al retrasar su asimilación (Bauer 1907: 320-330). Los argumentos de Bauer, como ya hemos visto, serían usados por los adversarios del partido Social Demócrata Judío, el PPS-Fracción Revolucionaria y el PPSD. A su vez Kautsky, en un trabajo que polemizaba con el de Bauer en aspectos generales de la teoría nacional, decía sobre los judíos:

(...) el Judaísmo era, en sus orígenes, una nación con un lenguaje común, que después devino una comunidad religiosa que asimiló miembros de diferentes

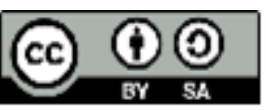


naciones, y después fue también asimilada por diferentes naciones. Cuando la cristiandad frenó la habilidad de la comunidad religiosa judía de expandirse (...) los judíos devinieron una raza específica: en la medida que la reproducción sexual en el matrimonio por fuera de la comunidad religiosa judía fue prohibida. Como representantes de la economía monetizada (...) el Judaísmo también tomó la forma de una ocupación específica (...) esto puede ser mucho mejor entendido usando el término casta antes que el de nación.

Los intentos de levantar al Judaísmo como nación son realmente únicamente intentos de mantener su existencia como una casta específica. Dichos esfuerzos serían inexplicables en un estado moderno. Sólo puede florecer bajo las condiciones de la burocracia moscovita (Kautsky 1908: 378).

Así, desde una posición teóricamente distinta, tendía acordar con un planteo asimilacionista. La desautorización de las posiciones nacionales del Bund y el ŻPSD por parte de los principales teóricos de la Social Democracia alemana y austríaca le complicarían enormemente la tarea de legitimarse a esta última organización.

En 1908, el PPSD aprobó el rearmado de su sección judía, renombrándola como "Social Democracia Judía de Galitzia", en un abierto intento de competir con el ŻPSD. Estos últimos constituían claramente la organización política dominante en el campo del proletariado judío en Galitzia. En su Congreso de 1908, el ŻPSD afirmaba tener 3500 miembros. El Partido Poale Zion de Austria afirmaba tener la misma cantidad de miembros en ese año, pero muchos de ellos vivían fuera de Galitzia (Kuhn 2011: 63).

A pesar de los desplantes del PPSD, el ŻPSD todavía estaba dispuesto a trabajar con ellos. En 1911 aceptó comenzar un proceso de fusión con la Sección Judía del mismo. Parte del acuerdo implicaba no presentar candidatos propios y apoyar a los del PPSD. El estallido de la Primera Guerra desarticuló al ŻPSD, que resurgiría para fusionarse con el Bund en Polonia al finalizar el conflicto (Kuhn 2011: 65).

\section{Cuarta Parte: La Lucha por el reconocimiento ante la Internacional}

Tanto el Bund, como las distintas organizaciones del llamado "sionismo socialista", buscaron reconocimiento por parte de la Segunda Internacional, la cual estaba organizada como una estructura federativa de secciones nacionales. Si bien para todas las organizaciones socialistas era importante el reconocimiento por parte de la Internacional, para las organizaciones judías se convirtió en algo esencial ya que su representación era cuestionada. Normalmente, la definición de una sección en la Internacional se hacía a partir de un principio "nacional" subscripto a bases territoriales, en oposición a un principio únicamente "estatal" (así, había por ejemplo representación independiente de grupos 
polacos, que estatalmente pertenecían al Imperio Ruso). Nunca se reconoció el principio extra-territorial de nacionalidad (Mendelsohn 1964: 131-2).

Algunas organizaciones judías tenían representación al interior de la Internacional, sólo que lo hacían dentro de la sección del territorio al que correspondían. El Bund consiguió representación dentro de la sección de Rusia, la cual estaba subdividida en dos: una vinculada a la Social Democracia, y otra a los Social Revolucionarios. Es por esto que el Bund sólo encontraba representación en la medida en que formaba parte del RSDRP; cuando se cortaron los lazos entre ambas organizaciones en 1903, se puso en cuestionamiento el lugar del Bund. La disputa por los delegados se resolvió mediante un acuerdo que dividía los votos de los Social Demócratas. Así, el Bund logró tener representación independiente por un corto tiempo (Mendelsohn 1964: 137); probablemente, esto se debió al gran tamaño e influencia de la organización.

En 1906 cuando el Bund reingresa al RSDRP se vuelven a establecer las condiciones que existían antes de la ruptura; sin embargo, los bundistas pelearon por sostenerse como miembros independientes en la sección, lo cual fue concedido. También buscaron conseguir una representación independiente en el Buró Socialista Internacional, lo cual no fue concedido. A pesar de esto, el Bund actuó en forma independiente dentro de los Congresos, particularmente en el de 1907 en Stuttgart, cuando se debatió en torno a la inmigración de trabajadores. En esa discusión, avanzaron con la presentación de una propuesta que implicaba rechazar todos los intentos legales que frenan la inmigración, relacionándola con la fuerte discriminación racial existente en muchos países (Mendelsohn 1964: 138-9).

En ese mismo congreso se presentó otra cuestión de relevancia para el Bund. Mientras que hasta ese momento había sido el único partido que representaba al proletariado judío, en 1907 comenzaron a dirigirse a la Internacional los partidos social-Sionistas que habían surgido en Rusia después de la revolución de 1905, éstos eran: Poale Zion, el S.E.R.P, y el Partido Obrero Sionista Socialista (S.S). Las organizaciones sionistas, a diferencia del Bund, reclamaban ante la Internacional la creación de una sección judía, como parte del derecho a una representación como nación extra territorial (Mendelsohn 1964: 139).

Ante el pedido de ser admitidos en el Congreso, la Internacional resolvió en primer lugar que los sionistas que sólo podían ser representados en una sección nacional (Rusia); por su parte, la sub-sección socialdemócrata se negó a recibirlos dada su tradicional postura Antisionista. La sub-sección constituida por los Social Revolucionarios aceptó incorporar al S.E.R.P. Ante esto, el S.S. interpeló al Buró buscando su propio reconocimiento. La Internacional aceptó incorporar al S.S. como una voz consultiva dentro del Congreso de Stuttgart, lo que significó que, por primera vez, las organizaciones socialistas acepten en el seno de la Internacional a un partido con perspectiva sionista de manera independiente. No obstante, al interior de la sección rusa no hubo acuerdo sobre esa decisión, y apelaron al Buró a que revea la situación. Ante eso, el Buró decidió otorgarle esa potestad a S.S. de

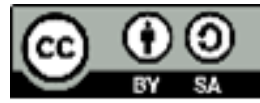


manera única para el Congreso de Stuttgart (Mendelsohn 1964: 141).

El debate sobre la sección judía continuó. El Bund se opuso a la demanda argumentando que la Internacional, al no reconocer a las nacionales extra-territoriales y al ser una organización política (no cultural), no podía contener a una sección judía. Por su parte, las organizaciones sionistas argumentaban que el reconocimiento que la Internacional otorgaba, el cual no estaba basado únicamente en la pertenencia estatal, podía incorporar a la nación judía. Además, arguiían que con la negación de la Internacional a incorporar a los judíos estaban desautorizando sus mismas resoluciones, ya que se había decidido reconocer el derecho a todas las nacionalidades a la autodeterminación. Con ese propósito, se mandaron cartas a la Internacional exigiendo su reconocimiento como nación, y se hicieron declaraciones públicas. Sin embargo, la Internacional se negó sistemáticamente a reconocerlas. De ahí que sólo las organizaciones judías que tenían vínculos orgánicos con las organizaciones socialistas nacionales pudieron tener representación en el seno de la Internacional, como fue el caso del Bund y del S.E.R.P (Mendelsohn 1964: 142). Esto implicó que en el plano internacional, también se vieran cuestionadas las organizaciones socialistas separadas para los judíos, en forma paralela a los casos nacionales.

\section{Conclusión: Convergencias y divergencias internacionales en torno a la cuestión partidaria y nacional}

En torno a la cuestión nacional judía, las organizaciones e intelectuales analizados oscilaron entre tres posturas principales: el asimilacionismo, el neutralismo, y el levantamiento de una identidad nacional judía. A su vez, estos planteos tenían relaciones cambiantes con dos planteos nacionales generales: la consigna de la autodeterminación nacional y la autonomía cultural nacional. Por último, estas polémicas normalmente estaban atadas a una concepción sobre la organización partidaria socialista: independencia organizativa para las naciones (que podía o no extenderse a los judíos) u organizaciones unificadas por territorio.

En cuanto a las posiciones de la Social Democracia Rusa, está claro que una de las motivaciones esenciales de la lucha contra el Bund tenía que ver con la negación al reconocimiento de una organización nacional separada. No obstante, en un primer momento, esto estaba interpretado en términos amplios, otorgándole al Bund derecho a tener sus propios Congresos y agitación en su idioma. Conectado con esto, el Congreso de 1903 postuló que el RSDRP apoyaba el derecho a la autodeterminación de las naciones, así como el derecho de éstas a tener escuelas propias y a usar su idioma en sus relaciones con la administración pública. Lejos de quienes interpretan que esto implicaba, meramente, un reconocimiento de un derecho abstracto (planteo que comparten el historiador moderno Gechtman (2008) desde un punto de vista sionista, y Luxemburg (1908) desde un punto de

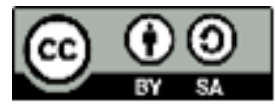


vista anti-nacional extremo), esta posición implicaba, en nuestra opinión, un reconocimiento principista de derechos nacionales junto a una necesaria flexibilidad táctica. En cuanto a la valoración sobre el futuro de la nacionalidad judía, Peled (1987) sostiene que la posición de Lenin y otros líderes del RSDRP, se basó no sólo en consideraciones organizativas sino en una teoría nacional general que sostenía una gradual desaparición de las diferencias nacionales como resultado del desarrollo del capitalismo. En este sentido, creemos que las posiciones generales de la RSDRP no pueden desprenderse este juicio, ya que el partido era bien consciente de la posibilidad de que una nación se reafirmara como resultado de una situación de opresión. Fue específicamente hacia los judíos que Lenin lanzó un pronóstico asimilacionista, primero en el curso de su lucha contra la autonomía del Bund en 1903, y más adelante en su crítica a un sistema escolar separado para los judíos. Junto a esto, desarrolló una fuerte crítica al sistema de la autonomía cultural-nacional proveniente del socialismo austríaco por considerarlo un nacionalismo disimulado, además de ser altamente ineficaz en términos organizativos. Así, se creó un cuadro que fue identificando progresivamente las posturas a favor de la autodeterminación nacional con la de un partido único multinacional, sostenido en muchos casos por posturas asimilacionistas (como la de Lenin), aunque sobre este último punto no existió una postura oficial del RSDRP. Frente a esto, el Bund, en primer lugar, planteó la postura de establecer una organización separada de los judíos (que no se extendía al resto de las nacionalidades de Rusia), para luego adherir a la teoría de la autonomía nacional cultural y, finalmente, dar el salto del neutralismo a una postura proclive a la afirmación de la nacionalidad judía.

En este marco, cabe destacar la evolución del Bund sobre estas cuestiones. Sus posiciones tempranas sobre la cuestión nacional judía, que se limitaban a la necesidad de agitación en su idioma, y a una formulación "neutralista", son poco objetables desde una postura favorable al Programa sobre las nacionalidades de 1903 de la Social Democracia Rusa; sin embargo, al unirse con posiciones afines a la Social Democracia austríaca, de sostener la separación por nacionalidad de las organizaciones socialistas y la autonomía culturalnacional como programa (que consideramos que fracasaron históricamente), crearon un divorcio con gran parte del resto de la Social Democracia Rusa que les impidió tener eficacia política. A su vez, estas posiciones fueron sostenidas en un ambiente acostumbrado a la organización socialista multinacional unificada, que llevó al Bund a sostener esta separación organizativa sólo para los judíos, siendo que era claro que esta posición fuera derrotada, en un marco donde se valoraba altamente la unidad organizativa por las condiciones de clandestinidad que la represión zarista imponía. Sin embargo, en un escenario donde el Sionismo ha alcanzado una preponderancia inusitada en la actualidad, creemos que los elementos internacionalistas y su lucha contra el Sionismo son elementos que merecen ser revalorizados, al tiempo que criticamos las posiciones políticas concretas en que la organización fue derivando.

En el socialismo polaco, la postura nacionalista del PPS implicó, en un primer momento, un

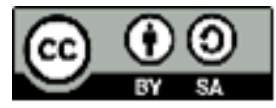


planteo asimilacionista polaco sobre los judíos, en contradicción con la propia resistencia del PPS ante la Social Democracia Rusa. Esto condujo a una interesante paradoja para el socialismo polaco, ya que debía defender su propio derecho a una independencia organizativa a la vez que negaba la de los judíos, lo cual los condujo a varios giros tácticos en torno a ese tema, antes de la ruptura del partido. Consumada la misma, el ala izquierda del partido continuó con el desarrollo de una postura favorable a la concesión de derechos autónomos para los judíos en Polonia, postura que puede ser considerada asimilacionista suave, en tanto reconocía la necesidad de derechos nacionales públicos para los judíos junto con una expectativa de asimilación por vía pacífica. Mientras que, el ala derecha del PPS, tuvo un giro crecientemente anti socialista acompañado por un asimilacionismo duro hacia los judíos polacos. En cuanto a la SDKPiL, sus miembros combinaron una postura clara en favor de la unidad organizativa socialista de todas las naciones por región (que conlleva cierta contradicción con sus demandas de autonomía frente a la Social Democracia Rusa) con una postura anti-nacional extrema opuesta tanto al enfoque de la autodeterminación nacional, como al de la autonomía nacional cultural. Sus posturas oficiales eran de un asimilacionismo suave, que enfatizaba la lucha contra el antisemitismo, a la vez que los escritos de Rosa Luxemburg contienen planteos bastante despectivos contra la cultura Yiddish. Así, tanto en sus versiones nacionalistas como anti-nacionalistas, el socialismo polaco osciló entre distintos matices de asimilacionismo, y tuvo distintos giros en torno al problema de la organización partidaria que oscilaron entre el intento de absorción y la aceptación de la independencia organizativa del Bund.

En Austria, la postura de Otto Bauer hacia la cuestión judía puede considerarse típica del partido Austro-alemán. El reconocimiento de un programa general sobre la autonomía cultural nacional concebida de forma extra territorial, junto a su negación para los judíos, constituía una contradicción aplastante, compartida, aunque desde un enfoque teórico distinto, por Kautsky. El intento de desarrollar un partido Social Demócrata Judío, que incluyera la lucha por la autonomía nacional cultural, hecho completamente "ortodoxo" en términos organizativos en Austria, no fue reconocido simplemente por la alianza de los elementos nacionalistas de la Social Democracia Austro-alemana y el PPSD y, en el caso de este último, por su identificación con las políticas del PPS. A su vez, al tomar el rumbo de organizar un partido separado dentro del área polaca (cuyos militantes tenían una posición más internacionalista e izquierdista que la media de su partido), coincidimos con Kuhn (1998; 2007; 2011) en que se perdió una oportunidad para desarrollar una oposición multiétnica a la orientación del PPSD en Galitzia. En general, consideramos que el sistema de partidos separados por nacionalidad, que resultaba la forma organizativa natural de las organizaciones que sostuvieran el programa de la autonomía cultural-nacional, resultó un fracaso en Austria ya que fue incapaz de solucionar las contradicciones entre las nacionalidades, y condujo a varias rupturas entre partidos socialistas nacionales que culminaron definitivamente en la ruptura de 1911 del Partido Pan-Austríaco.

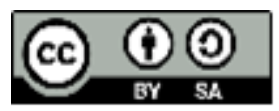


Cabe preguntarse si esta postura pro asimilación de los principales intelectuales de los partidos Social Demócratas Ruso, Polaco, Austro-Alemán y Austro-Polaco, no se correspondía socialmente con la intelligentsia asimilada que participaba, en grandes proporciones, en dichos partidos y en su liderazgo, reflejando cierta desconexión con la realidad del artesanado y la clase trabajadora que hablaba Yiddish de los países de Europa Oriental. En particular, estuvo carente el análisis de que la particular experiencia de opresión nacional y carencia de libertades democráticas básicas, llevó a un florecimiento de una consciencia nacional en los judíos de Europa Oriental. En este sentido se plantea el debate de si era posible combatir la forma sionista de canalizar este florecimiento sólo mediante una postura asimilacionista, o esto implicaba la necesidad de conducir un florecimiento de la cultura nacional Yiddish en un sentido nacionalista, o si era posible una postura favorable al desarrollo cultural del Yiddish y los elementos nacionales judios junto con un rechazo del aislacionismo y la organización nacional separada, postura que no fue asumida por ninguna organización.

Nuestro trabajo, al comparar varios casos, permite analizar en forma novedosa estos conflictos, revelando elementos que recorren todos los casos. Para los socialistas, el tema crucial que fomentó las grandes polémicas fue la unidad organizativa, que tenía una relación dialéctica con la situación de distinción nacional particular de la población judía de la zona, con cada factor reforzando al otro. El proyecto de partidos judíos en uniones federales fue rechazado por las organizaciones socialistas en todos los casos por motivos distintos: en Rusia, por su asociación con la autonomía nacional cultural y su separatismo organizativo; en Polonia, por las contradicciones de estos partidos en torno a la cuestión nacional y sus consecuencias organizativas; en Galitzia, por los elementos chauvinistas que tenían peso en los partidos socialistas nacionales de Austria. A su vez, la Segunda Internacional tampoco brindó un reconocimiento separado a las organizaciones judías en sí. De esta forma, el impulso de las organizaciones judías separadas terminó en el aislamiento político y organizativo de sus miembros, a la vez que alcanzaban un gran desarrollo numérico y en inserción de masas. Por otro lado, los principales referentes del pensamiento marxista de la época (Bauer, Kaustky, Luxemburg, Lenin) tuvieron dificultades para pronosticar adecuadamente el futuro del despertar nacional Yiddish, ya que identificaron correctamente las causas de su existencia en las condiciones económicas y sociales de atraso y pervivencia de formas no capitalistas o proto capitalistas en Europa del Este, pero no advirtieron que, por la dinámica particular del desarrollo desigual y combinado de estas zonas, ese despertar se daba en un momento de desarrollo del capitalismo, combinando varios factores: en primer lugar, se dio en la era del imperialismo, que agudizaba el conjunto de las contradicciones nacionales; en segundo lugar, en sociedades que no resolverían rápidamente los aspectos contradictorios de su desarrollo social; y, en tercer lugar, en marcos estatales de severa opresión contra los judíos que le daban a este despertar nacional una profundidad muy grande, al no existir un acceso fácil al asimilacionismo para

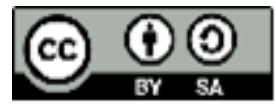


la masa de la población judía trabajadora de estas zonas, vía que sí fue posible para los miembros de la intelligentsia. La demostración del carácter estructural de este despertar nacional Yiddish, es que continuó largamente en décadas posteriores. Hizo falta el golpe del Holocausto, que asesinó a muchos de los hablantes de este idioma y la desterró casi totalmente de Europa, y la presión del sionismo en contra de este idioma y cultura, para sacarla de su lugar principal en la cultura judía de Europa del Este; y, aún así, no alcanzaron a borrarla del todo, ya que tuvo continuidad fuera de Europa ${ }^{23}$. De esta manera, ni en el plano de la organización y la militancia práctica, ni en el plano teórico, se dieron los elementos que permitieran la combinación de un acercamiento favorable al despertar nacional de las masas trabajadoras judías con su canalización en un sentido antiaislacionista e internacionalista.

\section{Bibliografía y documentos}

Bauer, O. (1907) [2000]. The Question of Nationalities and Social Democracy. Editado e introducido por Nimni, E. Minneapolis, University of Minnesota Press.

Blobaum, R. (1992). "The SDKPiL and the Polish Question (Revisited)" en John Morison (ed.), (1992), Eastern Europe and the West: Selected Papers from the Fourth World Congress for Soviet and East European Studies, Harrogate, 1990. London, St. Martin's Press: 207-218.

Broué, P. (1973). El partido bolchevique. Madrid, Editorial Ayuso.

Bund (1901). The Fourth Congress of the General Jewish Workers' Union in Russia and Poland. Versión inglesa en Mullin (2015): 306-312.

Davis, H. B. (1976). The National Question - Selected Writings by Rosa Luxemburg. New York and London, Monthly Review Press.

Gechtman, R. (2008). "A "Museum of Bad Taste"? The Jewish Labour Bund and the Bolshevik Position Regarding the National Question, 1903-14". Canadian Journal of History, 43(1): 31-67.

Gorny, Y. (2012). Converging Alternatives: The Bund and the Zionist Labor Movement, 1897-1985. SUNY Press.

Harding, N. y Taylor, R. (1983). Marxism in Russia. Key Documents 1879-1906. Cambridge, Cambridge University Press.

Kautsky, K. (1908). "Nationality and Internationality". Editado y traducido por Lewis, B. en Critique, 37: 3, 371-389, 2009.

Kogan, Arthur G. (1949), "The Social Democrats and the Conflict of Nationalities in the Habsburg Monarchy”, The Journal of Modern History, Vol. 21, No. 3, Sep., 1949: 204-217.

Kremer, A. y Martov, Y. (1896).On Agitation. Versión inglesa en Harding y Taylor (1983):192-

\footnotetext{
${ }^{23}$ Ver Gorni (2012), para las posturas del sionismo frente al Yiddish y su cultura, y Lipphardt (2011) para el devenir del Yiddish antes y después del Holocausto
} 
205.

Kuhn, R. (1998). Jewish socialists in Galitzia and Marxist debates over the national question before World War I. Paper for the Political Thought and Capitalism Seminar University of Newcastle, 17-19 February.

Kuhn, R. (2007). Henryk Grossman and the recovery of Marxism. Champaign,University of Illinois Press.

Kuhn, R. (2011). "Jewish Anti-Zionism in the Galitzian Socialist Movement". En Grabski, A. (Ed.). (2011) Rebels against Zion: Studies on the Jewish Left Anti-Zionism: 47-65.

Lenin (1903a). "A propósito de una declaración del Bund”, Iskra, № 33, 1 de Febrero, 1903, versión en castellano en Lenin (1970), Tomo 6: 344-350.

Lenin (1903b). “¿Necesita el proletariado judío un ’Partido Político Independiente’?”. Iskra, N $\mathrm{N}^{\circ} 34$, 15 de Febrero, 1903, versión en castellano en Lenin (1964), Tomo 6: 355-360.

Lenin (1903c). "El problema nacional en nuestro programa". Iskra, No 44, 15 de Julio, 1903, versión en castellano en Lenin (1970), Tomo 6: 480-91.

Lenin (1903d). "Intervención sobre el lugar que debe ocupar el Bund en el RSDRP”. II Congreso del RSDRP, 20 de julio, 1903, versión en castellano en Lenin (1970), Tomo 6: 426-29.

Lenin (1903e). "Proposiciones para los puntos sobre las reivindicaciones políticas generales del programa del partido". II Congreso del RSDRP, 30 de Julio, 1903, versión en castellano en Lenin (1970), Tomo 6: 535.

Lenin (1903f). "La última palabra del nacionalismo bundista". Iskra, № 46, 15 de Agosto, 1903, versión en castellano en Lenin (1970), Tomo 6.: 581-584.

Lenin (1903g). "El lugar del Bund dentro del Partido". Iskra, N 51, 22 de Octubre, 1903, versión en castellano en Lenin (1970), Tomo 7: 101-12.

Lenin (1906a). "La unión del Bund con el Partido Obrero Socialdemócrata Ruso". Primera quincena de Septiembre, 1906, versión en castellano en Lenin (1970), Tomo 11: 200-1.

Lenin (1906b). "Acerca de un artículo publicado en el órgano del Bund". Proletary, N ${ }^{\circ}$ 10, 20 de Diciembre, 1906, versión en castellano en Lenin (1970), Tomo 11: 409-26.

Lenin (1913a). "La clase obrera y el problema nacional". Pravda, № 16, 10 de mayo, 1913, versión en castellano en Lenin (1970), Tomo 19: 293-4.

Lenin (1913b). “¿Ha ofrecido pruebas Pravda del separatismo de los bundistas?”. Pravda, 5 de Junio, 1913, versión en castellano en Lenin (1970), Tomo 19: 410-1.

Lenin (1913c). "El problema Nacional". Cinas Bierds, No 4, Agosto, 1913, versión en castellano en Lenin (1970), Tomo 19: 331-4.

Lenin (1913d). "La nacionalización de escuelas judías". Pravda, №14, 18 de agosto, 1913, versión en castellano en Lenin (1970), Tomo 20: 55-6.

Lenin (1913e). "Resolución sobre el problema nacional". Comunicado y resoluciones de la Reunión de verano de 1913 del Comité Central del RSDRP con funcionarios del partido, Septiembre 1913, versión en castellano en Lenin (1970), Tomo 20: 183-6. 
Lenin (1913f). "La autonomía 'cultural-nacional". Pravda, № 46, 28 de noviembre, 1913, versión en castellano en Lenin (1970), Tomo 20: 262-5.

Lenin (1970). Obras Completas. Madrid, Editorial Akal.

Lipphardt, A. (2011). Yiddish after the Holocaust. Europa ethnica, 3-4: 80-87

Luxemburg, R. (1898) [1977]. The Industrial Development of Poland. New York, Campaigner Publications.

Luxemburg, R (1905). Foreword to the Anthology: The Polish Question and the Socialist Movement. Versión inglesa en Davis (1976): 60-100.

Luxemburg, R (1908). The Right of Nations to Self-Determination. Versión inglesa en Davis (1976): 101-158.

Luxemburg, R. (1909). The National Question and Autonomy. Versión inglesa en Davis (1976): 251-288.

Mendelsohn, E. (1964). "The Jewish Socialist Movement and the Second International, 1889-1914: The Struggle for Recognition". Jewish Social Studies: 131-145.

Mullin, R. (2015). The Russian Social-Democratic Labour Party, 1899-1904: Documents of the 'Economist' Opposition to Iskra and Early Menshevism. Leiden, Brill.

Nettl, J. P. (1966). Rosa Luxemburg Vol 1.Oxford, Oxford University Press.

Pearce, B. (1978), Second Ordinary Congress of the R.S.D.L.P., 1903: Complete Text of the Minutes. London, New Park Publications.

Poslednie Izvestiia (1903a). No. 105, Año 2, 28/15 de Enero. Versión inglesa en Mullin (2015): 316-318.

Poslednie Izvestiia (1903b). No. 106, Año 2, 3 de Febrero/21 de Enero. Versión inglesa en Mullin (2015): 318-319.

Peled, Y. (1987). "Lenin on the Jewish Question: The Theoretical Setting", en Political Studies, 35(1): 61-78.

RSDRP (1898). Decisions of the first congress of the RSDLP. Versión inglesa en Harding y Taylor (1983): 225-226.

Snyder, T. (1997). "Kazimierz Kelles-Krauz (1872-1905): A pioneering scholar of modern nationalism". Nations and Nationalism, 3 (2): 231-250.

Zimmerman, J. D. (2004). Poles, Jews, and the Politics of Nationality: The Bund and the Polish Socialist Party in Late Tsarist Russia, 1892-1914. Wisconsin, University of Wisconsin Press. 